\title{
EIG'NER HERD IST GOLDES WERT \\ EIN AUSSERGEWÖHNLICHER FRÜHEISENZEITLICHER BEFUND AUS DER SIEDLUNG IN JANOWICE, FDST. 6 (AZP 106-65/61), POLNISCHE WESTKARPATEN
}

\section{Marta Korczyńska - Maria Lityńska-Zając - Magdalena Moskal-del Hoyo}

DOI: https://doi.org/10.31577/szausav.2019.suppl.1.17

Keywords: Lusatian culture, Early Iron Age, daub, housing structures, anthracology, carpology

There is no place like home : Untypical Early Iron Age feature at the settlement in Janowice 6 (AZP 106-65/61) in Polish Western Carpathians

Feature 6, dated to the older phase of the Early Iron Age and located in trench 4 at the settlement in Janowice, site 6 (western Lesser Poland), is an outstanding structure mostly because of the large amount and uncommon size of the construction daub discovered in its infill. The inventory of the pit: loom weights, pestles and pottery types that might be associated with the course of processing activities rather than with storage vessels, point to daily activities of the household level. This paper focuses on the analysis of form and technology of daub from the pit and its interpretation. The remains of construction elements were analyzed in the context of adjacent postpits and accompanying findings - not only artefacts, but also charred plant macro-remains and their imprints in daub (carpology and anthracology). The study of these elements allowed to understand how these features functioned in the past. As a result, underneath the cultural background, we present a compilation of reconstruction possibilities of the structure that include integrated "heating installation" in the form of an oven, a hearth-plate, or a roaster.

\section{EINFÜHRUNG}

Auf den meisten spätbronze- und früheisenzeitlichen Siedlungen im westlichen Kleinpolen können keine Grubenhäuser oder deutliche Pfostenreihen, die Hausstrukturen entsprechen, beobachtet werden. Anhand der räumlichen Verteilung von Abfallgruben und vereinzelt erhaltenen Pfosten lässt sich nur so viel über die Gebäudekonstruktionen sagen, wie die allgemeine Vermutung, dass es sich um überirdische Bauweisen handelt, die keine Spuren hinterlassen haben. Trotzdem wurde während der Fundstellenbearbeitung oft der in den Abfallgruben deponierte Hüttenlehm ausgelassen. Dabei zeigen die neusten Studien, dass das Rotlehmmaterial trotz sekundärer Lage nicht nur technische Informationen bezüglich der Hausbauweise, sondern auch Hinweise zur Subsistenzwirtschaft der betreffenden prähistorischen Gesellschaften liefert (vgl. z. B. Dziegielewski 2010a; 2013; Haller/Gentizon/Kuna 2007; Haller/ Gentizon-Haller 2012; Vařeka 2012). In dem folgenden Artikel werden wir uns dem Konstruktionshüttenlehm widmen, der aus einem Befund stammt, welcher an den Anfang der Früheisenzeit zu datieren ist und aus mehreren Gründen eine Ausnahmesituation innerhalb des Befundgefüges der Siedlung in Janowice, Fdst. 6 (AZP Nummer 106-65/61), bildet. Anhand der Lage der Hüttenlehmfragmente in einer Grube sowie der Analyse der technologischen und typologischen Merkmale der Rotlehmfragmente, bei denen Konstruktionsabrücke nachgewiesen werden konnten, sowie der gleichzeitigen Verfüllung von Stein ${ }^{1}$ - und Keramikfunden, Holzkohle und verkohlten makroskopischen Pflanzenresten werden mögliche Hypothesen bezüglich der Ansprache der Struktur vorgeschlagen.

\footnotetext{
1 Es handelt sich hierbei um Poch- oder Reibsteine, die in diesem Artikel nicht näher beschrieben werden (vgl. Wasilewski
} 2014, Tab. 1). 


\section{LAGE DER FUNDSTELLE}

Bei der Fundstelle in Janowice, Fdst. 6 (AZP 106-65/61), handelt es sich um eine Höhensiedlung großer Ausdehnung in markanter Spornlage über dem Tal des Dunajec und dem südlich gelegenen Becken von Zakliczyn (Abb. 1). Nach ersten Prospektionsarbeiten 2006 wurden hier in den Jahren 2007-2011 Ausgrabungen durchgeführt, die einen guten Überblick über die bronze- und früheisenzeitliche Besiedlung der Fundstelle vermitteln. Aufgrund der neun Grabungsschnitte, die eine Fläche von 14 Ar umfassen, der räumlichen Verteilung der Oberflächenfunde sowie der Ergebnisse der geomagnetischen Prospektion ist auf einer Länge von mindestens $900 \mathrm{~m}$ des grob NW-SO verlaufenden Plateaus und im oberen südlich bzw. südwestlich exponierten Hangbereich mit den Überresten von Siedlungsaktivitäten zu rechnen, die eine Laufzeit von mehreren hundert Jahren umfassten (vgl. Kienlin u. a. 2010).

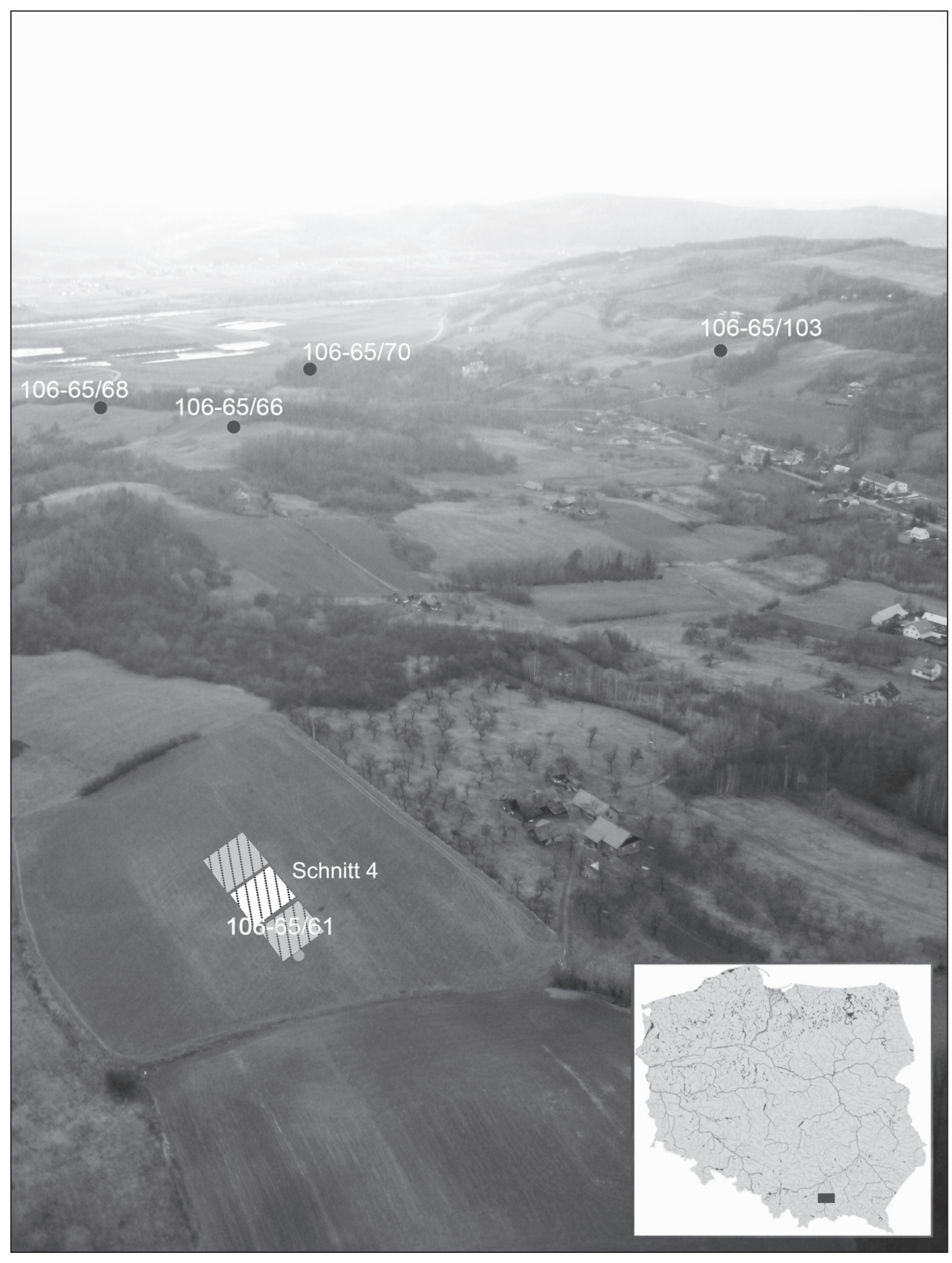

Abb. 1. Blick auf die Siedlung in Janowice, Fdst. 6 (AZP 106-65/61), und umliegende Fundstellen Richtung Nordwesten (Photo K. Cappenberg). 


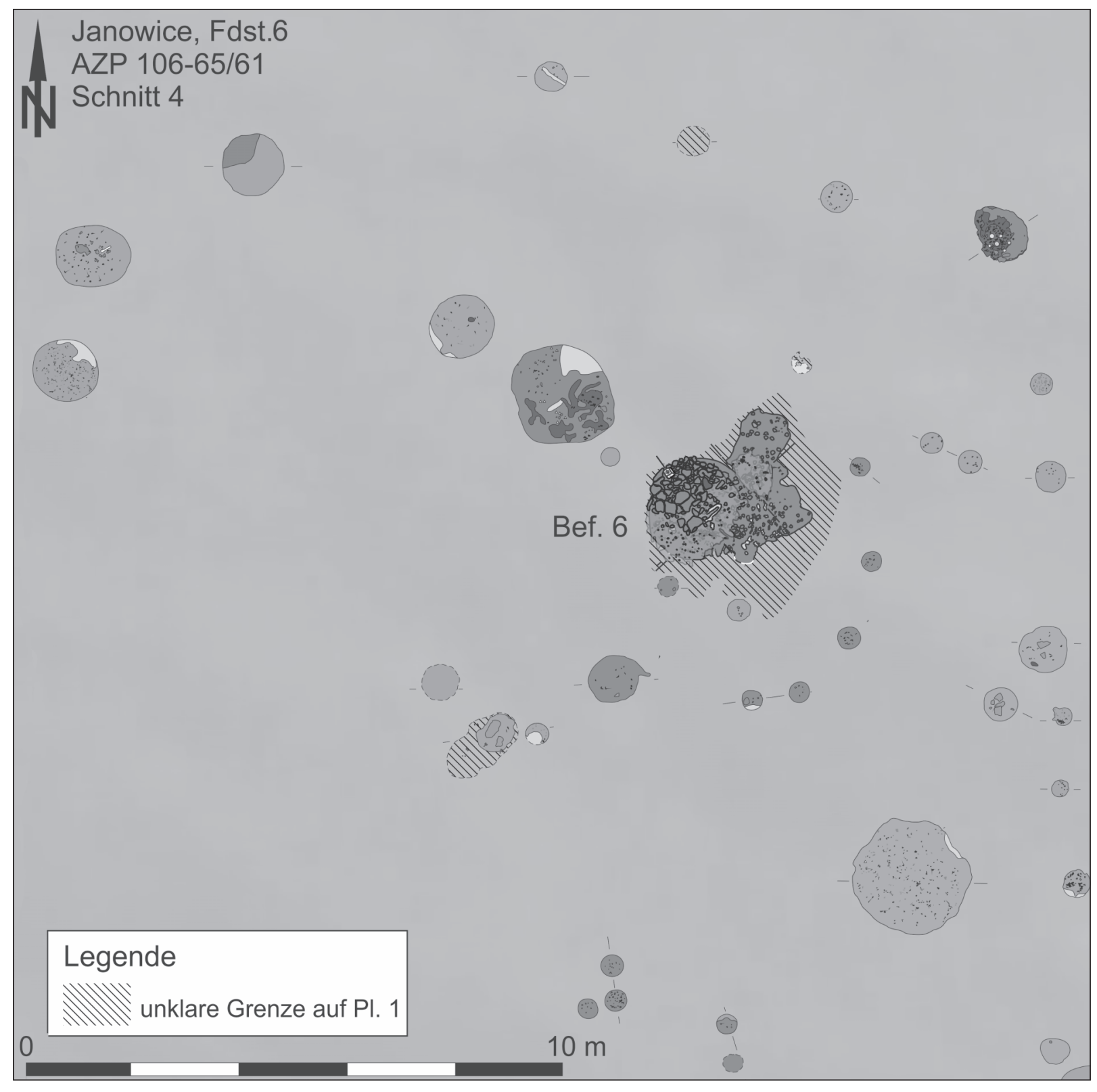

Abb. 2. Janowice, Fdst. 6 (AZP 106-65/61), Plan des Schnittes 4.

Im Jahr 2008 wurde in Schnitt 4 eine Grube dokumentiert, die sich unter anderem durch eine große Menge an Konstruktionshüttenlehm auszeichnete (Befund 4/6, Abb. 2). Das Gewicht der geborgenen Fragmente beträgt fast $40 \mathrm{~kg}$ und überschreitet damit deutlich die Gesamtmasse des Rotlehms aller anderen Befunde, die auf der Siedlung in Janowice untersucht wurden² (Abb. 3).

\section{BEFUNDBESCHREIBUNG}

Befund 4/6 wies auf Planum 1 eine unregelmäßige Form mit einer Ausdehnung von ca. 3,5 m x 4,5 $\mathrm{m}$ auf (auf der Taf. I mit einer Schraffur abgebildet), die sich auf Zwischenplanum 1-2 im SW Teil als

2 In der Zusammenstellung sind die Befunde, die während der Kampagne 2007 untersucht wurden, nicht berücksichtigt -im Fall der vorgestellten Strukturen ist der überwiegende Teil des Rotlehmmaterials nach der Grabungskampagne verloren gegangen. Außerdem konnte aus technischen Gründen nur ein Teil des Rotlehmmaterials aus der Grube 4/6 eingesammelt werden. Das Gesamtgewicht des Hüttenlehms kann anhand der Felddokumentation auf 80-120 kg geschätzt werden. 
eine kreisförmige Struktur mit ca. 2 m Durchmesser darstellte (Taf. I). Dem Befund wurden drei Profile zugewiesen und alle Befundteile wurden mit künstlichen Abträgen von $10 \mathrm{~cm}$ ausgegraben und dokumentiert. Die hellbraune Verfärbung der Grube zeigte bereits auf Planum 1 mehrere Einschlüsse von Rotlehm- und Holzkohlefragmenten. Im Nord-West Bereich der oben genannten kreisförmigen Struktur fand sich auf dem Niveau von Planum 2 eine kompakte Hüttenlehmpackung. Während der Bergung war feststellbar, dass sich die Hüttenlehmfragmente extrem schwer voneinander trennen ließen. Anhand der Profile wurden zwei unterschiedliche Formen der beiden Teile des Befundes festgestellt: die ca. 50 $\mathrm{cm}$ tiefe, kreisförmige Grube im Süd-West Teil des Befundes hatte einen wannenförmigen Abschluss, während bei der flachen Struktur im östlichen Bereich ein flacher Boden beobachtet werden konnte. Der Befund wurde weder mit Steinen verkleidet, noch konnte eine große Hitzeeinwirkung in der Grube selbst festgestellt werden.

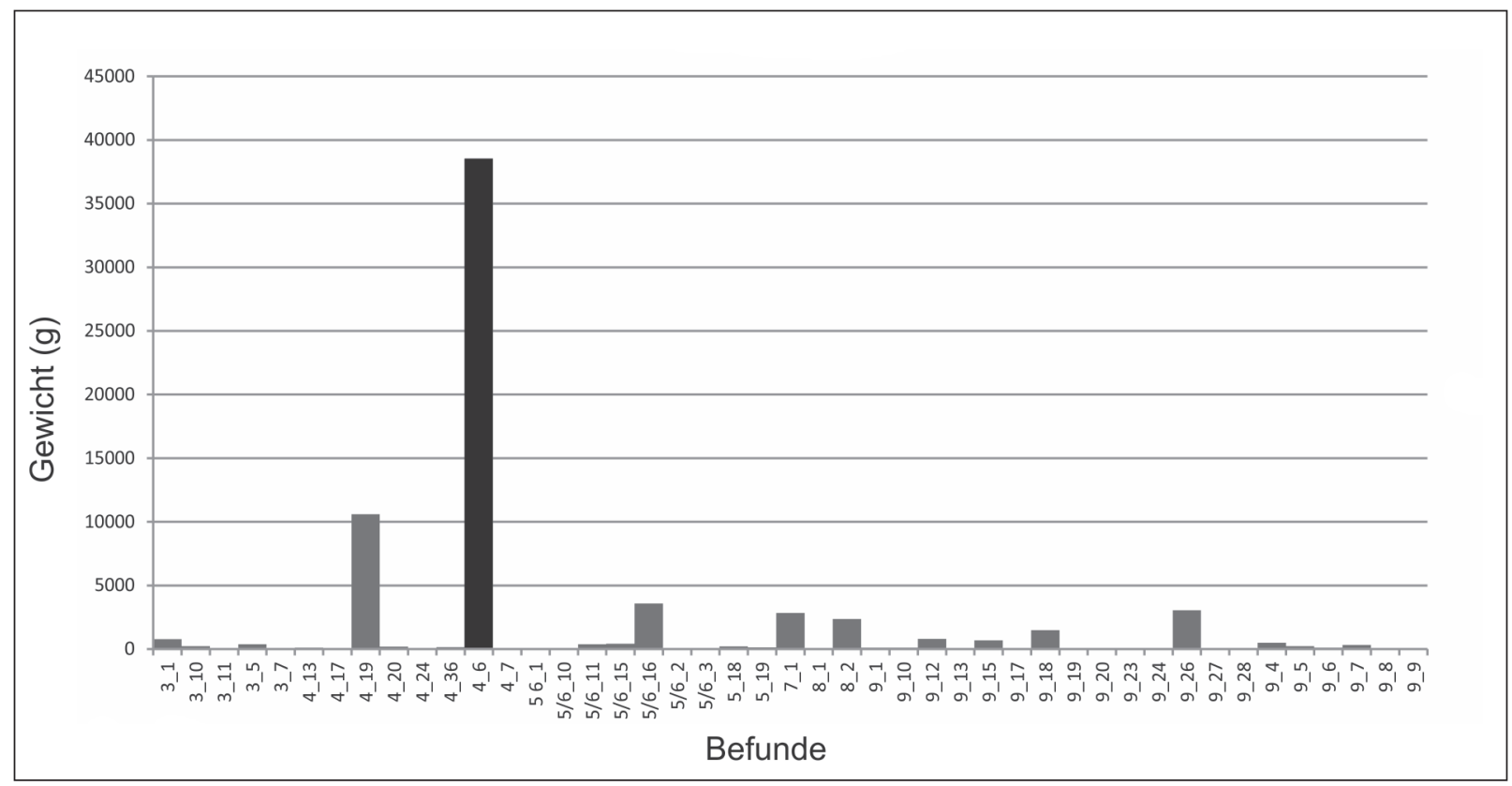

Abb. 3. Vergleich des Rotlehmgewichtes aus den Befunden im Schnitten 3-9 in Janowice, Fdst. 6 (AZP 106-65/61).

\section{FUNDINVENTAR}

\section{Stilistik und Chronologie der Keramikgefäße}

Aus allen Bereichen des Befundes wurden insgesamt nahezu 200 Keramikscherben geborgen, darunter Fragmente, die von mindestens zwei Tonscheiben stammen, ein mit kleinen Hornknubben verziertes Miniaturgefäß, Fragmente von konischen Schalen mit verdicktem Rand und Topfbodenfragmente sowie ein Bauchstück mit einer Leiste, die mit Fingerabdrücken verziert wurde, welches vermutlich ebenso von einem Topf stammt (Taf. II). Die erwähnten Gefäßformen, vor allem die Tonscheiben und Töpfe könnten eine Funktion während der Vorbereitung von Mahlzeiten gehabt haben. Konische Schalen dagegen werden oft in der Literatur mit dem Verzehren des Essens verbunden (Griebl 2004, 166).

Hornknubben wurden auf der Siedlung Janowice 6 auch in anderen Befunden festgestellt (Kienlin u. a. 2010, 236, 237, Taf. 14: 4; 19: 1). Im unteren Dunajectal ist ein mit massiven Hornknubben verzierter Topf auch aus der spätbronzezeitlicher Siedlung in Wojnicz 48 bekannt (Dziegielewski 2010a: Taf. I: c), diese Verzierung ist zudem sehr oft auf unterschiedlichen Gefäßen in Wierzchosławice 15 anzutreffen (Miraś/Oleszczak 2014, Abb. 7-9). Im oberen Dunajectal tritt sie in den Siedlungen in Nowy Sącz-Biegonice 20 (Cabalska/Madyda-Legutko/Tunia 1990, Abb. 5: c; 8: j) und Maszkowice 1 in der VI und VII Phase auf (Skoneczna 2014, Taf. 16: 14; 27: 16; 31: 14; 32: 11). Im südlichen Kleinpolen lassen sich Hornknubben mit der stilistischen Phase Maszkowice 6, die der Wende zwischen Ha B3/Ha C und Ha C entspricht, synchronisieren (Kienlin u. a. 2010, 236, 237; Przybyła, M. S./Przybyła, M. M. 2010, 546) und werden als Ausdruck von Kontakten mit der Region Šariš und dem Ostslowakischen Tiefland interpretiert (Dzięgielewski 2010a, 75; 
Przybyła, M. S. 2009, 245, 246), denn weitere Vergleichsfunde sind in den Materialien der früheisenzeitlichen Fundstellen aus der Ostslowakei, besonders aus der Siedlung in Terňa, Kr. Prešov (Budinský-Kričkal Miroššayová 1992) zu finden.

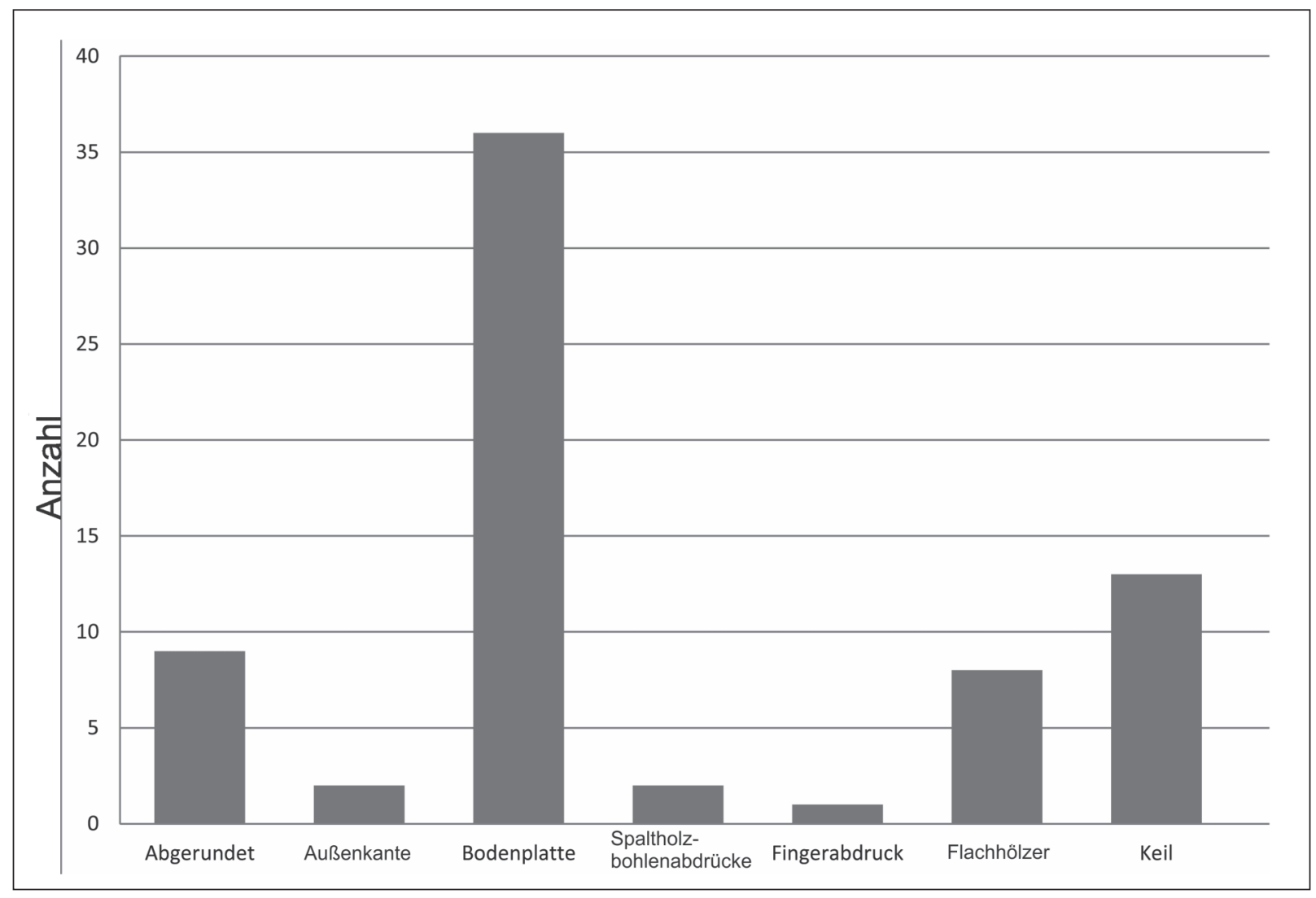

Abb. 4. Verteilung der Abdrücke im Konstruktionsrotlehm aus dem Befund 4/6.

Man muss darauf hinweisen, dass zwar manche Motive, wie Leisten mit Abdrücken oder Gefäßformen wie Schüsseln mit verdicktem Rand auch in den jüngeren Zeithorizont Ha D bis LT A - datiert werden könnten (Zabrzeż-Podegrodzie Phase nach Madyda-Legutko 1995, s. auch Dzięgielewski 2010b; Dzieggielewski/Godlewski 2009; Jędrysik u. a., im Druck), jedoch scheint in unserem Kontext eine derart späte Datierung eher fraglich zu sein. Darüberhinaus verweisen die Ergebnisse der ${ }^{14} \mathrm{C}$ Datierung auf die Periode zwischen 800 und 550 v. Chr., zeigen also auf den der Phase Ha C entsprechenden Zeitabschnitt (Taf. I).

Insgesamt sollte daher das Fund material der Grube 4/6 mit dem Zeitabschnitt Ha C, unter Umständen mit dem Anfang des älteren Abschnittes von Ha D in Verbindung gebracht werden.

\section{Webgewichte}

Obwohl aus dem Befund nur ein komplett erhaltenes und zwei sehr kleine Fragmente von Webgewichten geborgen wurden, lässt der starke Zerstörungsgrad des Fundensembles vermuten, dass in dem Befund Überreste von einem Webstuhl deponiert worden sein könnten. Trotzdem, ein Beweis für die Deutung der kreisförmigen Vertiefung als Webstuhlgrube ist nicht vorhanden (vgl. Korczyńskal Mazur 2018). Es soll allerdings angemerkt werden, dass die Verortung des Webgewichtes in eine Schicht direkt über den verbrannten Konstruktionsrelikten zeigt, dass das Gewicht kurz nach einem Brand (?) in den Befund geraten ist. Das 2908 g schwere Webgewicht (Taf. II) - wenn die abgebrochene Ecke hinzugerechnet würde, könnte das Gesamtgewicht auf $3000 \mathrm{~g}$ steigen - mit annähernd quadratischer Kopf- und Bodenfläche, ist aus mit Schamotte gemagertem Ton gefertigt worden und höchstwahrscheinlich sekundär gebrannt. Seine Oberfläche wurde grob geglättet und auf der flachen Kopffläche wurden 
durch Fingereindrücke mehrere Vertiefungen geschaffen, die einen Kreis mit einem Mittelpunkt bilden (s. auch Korczyńska/Mazur 2018). Obgleich diese Verzierung auf Hallstattkeramik oft zu beobachten ist, z. B. in der ostslowakischen Siedlung Terňa-Lysá Stráž (Budinský-Krička/Miroššayová 1992, Taf. 4: 27), kommt sie dennoch auf pyramidenförmigen Webgewichten relativ selten vor.

Das Webgewicht aus Janowice findet die nächste Analogie auf der Fundstelle in Čečejovce (westliches Košicer Becken; Miroššayová 1994, 41, 53, Taf. 1: 22, 24), auch wenn es auf dem Fund aus der Slowakei nur sieben Punkte zu sehen gibt. Diese Siedlung kann jedoch den handgefertigten Keramikformen zur Folge (Miroššayová 1994, 54, 55), die im Theissgebiet und im westlichen Teil des Karpatenbeckens angetroffen werden können, in die Stufen Ha D3 bis LT A datiert werden. Hallstattzeitliche Weberei im Ostalpenraum weist ein große Anzahl reich verzierter stumpfpyramidenförmiger Gewichte auf (z. B. in Burgstallkogel, Grossweikersdorf, Oberleiserberg, Poštela, Rifnik oder Stillfried an der March, z. B. Dobiat 1990, 55, 56, Abb. 28; Teržan 1990, Taf. 23; 25; Stegmann-Rajtár 1998, 264, Abb. 7), auch wenn die Funktion der Ornamentik der Webwichte bis jetzt noch nicht eindeutig erklärt wurde (s. auch Korczyńska/Mazur 2018, dort weitere Literatur). Die westslowakischen verzierten Webgewichte, wie die Funde aus Smolnice-Molpír - darunter ein sehr kleines Exemplar mit fünf eingestochenen Punkten auf der Kopffläche - wurden als Ergebnis des Kontaktes innerhalb des Osthallstattkulturkreises interpretiert (Stegmann-Rajtár 1998, 275, Abb. 3: 3). Die mit mehreren (zwei oder fünf) auf der Kopffläche eingestochenen Punkten versehenen Gewichte stammen dagegen aus der hallstattlicher Siedlung in Nové Košariská in der Slowakei (Belanovál Čambal/Stegmann-Rajtár 2007, Abb. 5), aus der ungarischen hallstattzeitlichen Siedlungen in Vát-Bodon (Ha C2-D1, Molnár/Farkaš 2010, Abb. 18: 5) und Győr-Ménfőcsanak (Ha C; Ďurkovič 2015, Abb. 5), oder aus der slowenischen hallstattzeitlichen Siedlung von Poštela (Teržan 1990, Taf. 9: 8; 23: 21; 27: 5, 6). Weitere Beispiele sind in einem Ha A2-zeitlichen Tongewichtenensemble aus Březnice in Böhmen zu finden, in dem sich Exemplare mit zwei bis acht Fingerabdrücken auf der Kopffläche befanden (Chvojka u. a. 2019, 279-283, Abb. 4; 8; 17).

\section{Hüttenlehm}

Die Fragmente, bei denen Konstruktionsabrücke nachgewiesen worden sind, wurden anhand von Form und technologischen Merkmalen beschrieben (Tabelle 1), die die innere Struktur und Art der makroskopisch sichtbaren Magerungspartikel umfassten. Alle Stücke sind auch gewogen worden, um die Fragmentierung des Materials zu erfassen. Auch die Farbe - ein Merkmal, das unter anderem von der Verbrennungstemperatur abhängig ist, wurde registriert.

Tabelle 1. Janowice, Fdst. 6 (AZP 106-65/61), Rotlehm mit Konstruktionsabdrücken aus dem Befund 4/6.

\begin{tabular}{|c|c|c|c|c|c|c|c|c|c|c|c|c|c|}
\hline 므 & 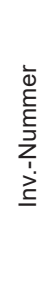 & 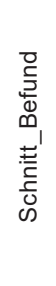 & $\overline{\bar{\oplus}}$ & 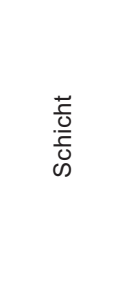 & 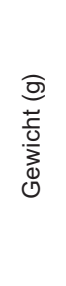 & $\begin{array}{l}\stackrel{0}{0} \\
\stackrel{0}{\frac{0}{\pi}} \\
\stackrel{4}{\leftarrow}\end{array}$ & 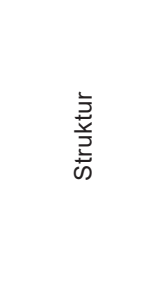 & 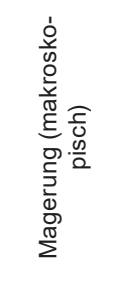 & 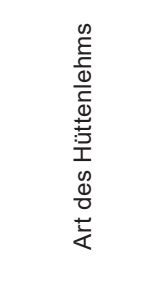 & 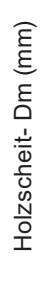 & 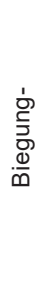 & 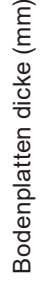 & 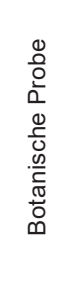 \\
\hline 7 & 433 & 4_6 & W-Mitte & $60-80 \mathrm{~cm}$ & 992 & $\begin{array}{c}\text { hellorange } \\
\text {-dunkelbraun }\end{array}$ & sehr kompakt & Glimmer & abgerundet & & & & B-5 \\
\hline 8 & 433 & 4_6 & W-Mitte & $60-80 \mathrm{~cm}$ & 1764 & beige-orange & kompakt & keine & Bodenplatte & & & 70 & B-5 \\
\hline 33 & 412 & 4_6 & W & $40-60 \mathrm{~cm}$ & 129 & hellorange & brüchig & organisch & $\begin{array}{l}\text { Spaltholzboh- } \\
\text { lenabdrücke }\end{array}$ & & & & \\
\hline 34 & 412 & 4_6 & W & $40-60 \mathrm{~cm}$ & 27 & $\begin{array}{l}\text { hellorange- } \\
\text { dunkelbraun }\end{array}$ & brüchig & organisch & flach & & & 26 & B-18 \\
\hline 35 & 412 & 4_6 & W & $40-60 \mathrm{~cm}$ & 57 & hellorange & brüchig & organisch & Keil & & & & \\
\hline 36 & 412 & 4_6 & W & $40-60 \mathrm{~cm}$ & 54 & hellorange & brüchig & organisch & Keil & & & & \\
\hline 37 & 412 & 4_6 & W & $40-60 \mathrm{~cm}$ & 36 & hellorange & brüchig & organisch & flach & & & 18 & \\
\hline 38 & 412 & 4_6 & W & $40-60 \mathrm{~cm}$ & 30 & hellorange & brüchig & organisch & Keil & & & & \\
\hline 40 & 412 & 4_6 & W & $40-60 \mathrm{~cm}$ & 52 & hellorange & brüchig & organisch & Keil & & & & B-19 \\
\hline 41 & 412 & 4_6 & W & $40-60 \mathrm{~cm}$ & 44 & beige-orange & kompakt & keine & Bodenplatte & & & 21 & \\
\hline 42 & 412 & 4_6 & W & $40-60 \mathrm{~cm}$ & 32 & hellorange & brüchig & organisch & Keil & & & & B-20 \\
\hline 43 & 412 & 4_6 & W & $40-60 \mathrm{~cm}$ & 33 & hellorange & brüchig & organisch & Keil & & & & \\
\hline
\end{tabular}


Tabelle 1. Weiterführung.

\begin{tabular}{|c|c|c|c|c|c|c|c|c|c|c|c|c|c|}
\hline 으 & 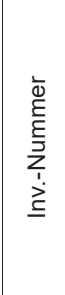 & 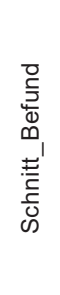 & $\overline{\bar{\oplus}}$ & $\begin{array}{l}\frac{\vec{J}}{0} \\
\frac{0}{\bar{J}} \\
\text { on }\end{array}$ & 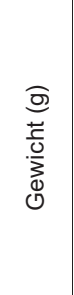 & 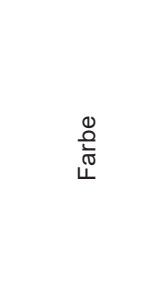 & 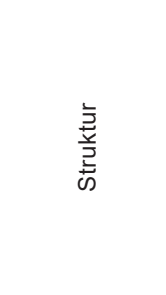 & 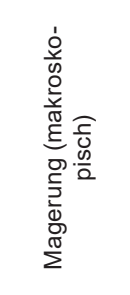 & 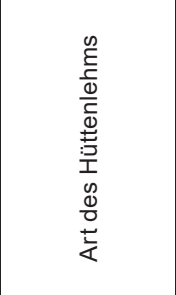 & 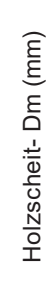 & $\begin{array}{l}\text { ర্ } \\
\stackrel{\complement}{5} \\
\frac{0}{\oplus}\end{array}$ & 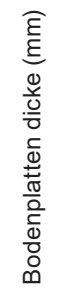 & 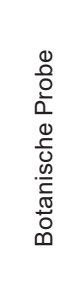 \\
\hline 44 & 406 & 4_6 & $W$ & $40-60 \mathrm{~cm}$ & 722 & beige-orange & kompakt & keine & Bodenplatte & & & 70 & \\
\hline 45 & 402 & 4_6 & $S$ & $40-50 \mathrm{~cm}$ & 25 & $\begin{array}{l}\text { dunkelbraun- } \\
\text { orange }\end{array}$ & $\begin{array}{l}\text { ziemlich } \\
\text { kompakt }\end{array}$ & organisch & Fingerabdruck & & & & \\
\hline 46 & 402 & 4_6 & $S$ & $40-50 \mathrm{~cm}$ & 105 & hellorange & brüchig & organisch & flach & & & 33 & \\
\hline 47 & 402 & 4_6 & $S$ & $40-50 \mathrm{~cm}$ & 103 & hellorange & brüchig & organisch & Keil & 110 & & & \\
\hline 48 & 402 & 4_6 & $\mathrm{s}$ & $40-50 \mathrm{~cm}$ & 48 & hellorange & brüchig & organisch & Keil? & 90 & & & \\
\hline 49 & 402 & 4_6 & $\mathrm{s}$ & $40-50 \mathrm{~cm}$ & 118 & hellorange & brüchig & organisch & flach & & & 34 & \\
\hline 50 & 401 & 4_6 & w & $50-55 \mathrm{~cm}$ & 80 & hellorange & brüchig & organisch & Keil & 110 & & & \\
\hline 51 & 401 & 4_6 & w & $50-55 \mathrm{~cm}$ & 76 & hellorange & brüchig & organisch & Keil & & & & \\
\hline 52 & 401 & 4_6 & w & $50-55 \mathrm{~cm}$ & 26 & hellorange & brüchig & organisch & flach & & & 20 & \\
\hline 53 & 401 & 4_6 & w & $50-55 \mathrm{~cm}$ & 19 & beige-orange & kompakt & keine & Bodenplatte & & & 18 & \\
\hline 54 & 401 & 4_6 & w & $50-55 \mathrm{~cm}$ & 43 & hellorange & brüchig & organisch & Keil & & & & \\
\hline 55 & 401 & 4_6 & w & $50-55 \mathrm{~cm}$ & 13 & hellorange & brüchig & organisch & $\begin{array}{l}\text { Spaltholzboh- } \\
\text { lenabdrücke }\end{array}$ & & & & \\
\hline 56 & 401 & 4_6 & w & $50-55 \mathrm{~cm}$ & 38 & hellorange & brüchig & organisch & Keil & & & & \\
\hline 58 & 401 & 4_6 & w & $50-55 \mathrm{~cm}$ & 38 & hellorange & brüchig & organisch & flach & & & & B-21 \\
\hline 59 & 401 & 4_6 & w & $50-55 \mathrm{~cm}$ & 17 & hellorange & brüchig & organisch & Außenkante & & & & \\
\hline 60 & $\begin{array}{l}419, \\
4124\end{array}$ & 4_6 & SW & $40-60 \mathrm{~cm}$ & 62 & $\begin{array}{c}\text { hellorange } \\
\text {-dunkelbraun }\end{array}$ & sehr kompakt & Glimmer & abgerundet & & 95 & & \\
\hline 63 & 424 & 4_6 & 0 & $40-60 \mathrm{~cm}$ & 78 & beige-orange & kompakt & keine & Bodenplatte & & & & \\
\hline 64 & 424 & 4_6 & 0 & $40-60 \mathrm{~cm}$ & 37 & nein & sehr kompakt & Glimmer & abgerundet & & & & \\
\hline 66 & 427 & 4_6 & $\mathrm{N}$ & $60-70 \mathrm{~cm}$ & 67 & beige-orange & kompakt & keine & Bodenplatte & & & & \\
\hline 67 & 427 & 4_6 & $\mathrm{N}$ & $60-70 \mathrm{~cm}$ & 51 & beige-orange & kompakt & keine & Bodenplatte & & & & \\
\hline 68 & 427 & 4_6 & $\mathrm{N}$ & $60-70 \mathrm{~cm}$ & 30 & hellorange & brüchig & organisch & Keil & & & & \\
\hline 69 & 427 & 4 4_6 & $\mathrm{N}$ & $60-70 \mathrm{~cm}$ & 193 & beige-orange & kompakt & keine & Bodenplatte & & & & \\
\hline 74 & 4124 & 4_6 & & $40-60 \mathrm{~cm}$ & 112 & $\begin{array}{l}\text { hellorange- } \\
\text { dunkelbraun }\end{array}$ & sehr kompakt & Glimmer & abgerundet & & 90 & & \\
\hline 78 & 428 & 4_6 & SW & & 31 & $\begin{array}{l}\text { hellorange } \\
\text {-dunkelbraun }\end{array}$ & sehr kompakt & Glimmer & abgerundet & & 150 & & \\
\hline 115 & 433 & 4_6 & W-Mitte & $60-80 \mathrm{~cm}$ & 880 & beige-orange & kompakt & keine & Bodenplatte & & & 52 & \\
\hline 116 & 433 & 4 4_6 & W-Mitte & $60-80 \mathrm{~cm}$ & 411 & beige-orange & kompakt & keine & Bodenplatte & & & 66 & \\
\hline 117 & 433 & 4_6 & W-Mitte & $60-80 \mathrm{~cm}$ & 349 & beige-orange & kompakt & keine & Bodenplatte & & & 64 & \\
\hline 118 & 433 & 4 4_6 & W-Mitte & $60-80 \mathrm{~cm}$ & 1570 & beige-orange & kompakt & keine & Bodenplatte & & & 115 & \\
\hline 119 & 433 & $4 \_6$ & W-Mitte & $60-80 \mathrm{~cm}$ & 549 & beige-orange & kompakt & keine & Bodenplatte & & & 60 & \\
\hline 120 & 433 & 4 4_6 & W-Mitte & $60-80 \mathrm{~cm}$ & 206 & beige-orange & kompakt & keine & Bodenplatte & & & 37 & \\
\hline 122 & 433 & 4_6 & W-Mitte & $60-80 \mathrm{~cm}$ & 868 & beige-orange & kompakt & keine & Bodenplatte & & & 77 & \\
\hline 123 & 433 & 4_6 & W-Mitte & $60-80 \mathrm{~cm}$ & 284 & hellorange & kompakt & Glimmer & Außenkante & & & 65 & \\
\hline 125 & 433 & 4_6 & W-Mitte & $60-80 \mathrm{~cm}$ & 1203 & beige-orange & kompakt & keine & Bodenplatte & & & 85 & \\
\hline 126 & 433 & 4_6 & W-Mitte & $60-80 \mathrm{~cm}$ & 782 & beige-orange & kompakt & keine & Bodenplatte & & & 68 & \\
\hline 127 & 433 & 4_6 & W-Mitte & $60-80 \mathrm{~cm}$ & 756 & beige-orange & kompakt & keine & Bodenplatte & & & 95 & \\
\hline 128 & 433 & $4 \_6$ & W-Mitte & $60-80 \mathrm{~cm}$ & 375 & beige-orange & kompakt & keine & Bodenplatte & & & 71 & \\
\hline 129 & 433 & 4_6 & W-Mitte & $60-80 \mathrm{~cm}$ & 2144 & beige-orange & kompakt & keine & Bodenplatte & & & 77 & \\
\hline 130 & 433 & 4_6 & W-Mitte & $60-80 \mathrm{~cm}$ & 774 & beige-orange & kompakt & keine & Bodenplatte & & & 72 & \\
\hline 131 & 433 & 4_6 & W-Mitte & $60-80 \mathrm{~cm}$ & 342 & beige-orange & kompakt & keine & Bodenplatte & & & 32 & \\
\hline 132 & 433 & 4 4_6 & W-Mitte & $60-80 \mathrm{~cm}$ & 139 & beige-orange & kompakt & keine & Bodenplatte & & & 56 & \\
\hline 133 & 433 & 4_6 & W-Mitte & $60-80 \mathrm{~cm}$ & 833 & beige-orange & kompakt & keine & Bodenplatte & & & 72 & \\
\hline 134 & 433 & 4_6 & W-Mitte & $60-80 \mathrm{~cm}$ & 73 & beige-orange & kompakt & keine & Bodenplatte & & & 48 & \\
\hline 135 & 433 & 4_6 & W-Mitte & $60-80 \mathrm{~cm}$ & 135 & beige-orange & kompakt & keine & Bodenplatte & & & 48 & \\
\hline 136 & 433 & 4_6 & W-Mitte & $60-80 \mathrm{~cm}$ & 963 & beige-orange & kompakt & keine & Bodenplatte & & & 81 & \\
\hline 137 & 433 & 4_6 & W-Mitte & $60-80 \mathrm{~cm}$ & 87 & beige-orange & kompakt & keine & Bodenplatte & & & 29 & \\
\hline 170 & 433 & 4_6 & W-Mitte & $60-80 \mathrm{~cm}$ & 41 & beige-orange & kompakt & keine & Bodenplatte & & & & \\
\hline 171 & 433 & 4 4_6 & W-Mitte & $60-80 \mathrm{~cm}$ & 58 & beige-orange & kompakt & keine & Bodenplatte & & & & \\
\hline 173 & 433 & 4_6 & W-Mitte & $60-80 \mathrm{~cm}$ & 1793 & beige-orange & kompakt & keine & Bodenplatte & & & & \\
\hline
\end{tabular}


Tabelle 1. Weiterführung.

\begin{tabular}{|c|c|c|c|c|c|c|c|c|c|c|c|c|c|}
\hline 으 & 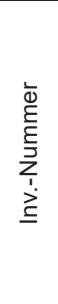 & 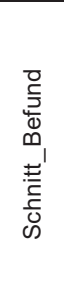 & $\overline{\bar{\sigma}}$ & $\begin{array}{l}\frac{\vec{t}}{0} \\
\frac{\vec{J}}{\mathrm{U}} \\
\text { c) }\end{array}$ & 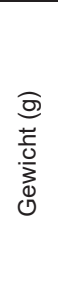 & 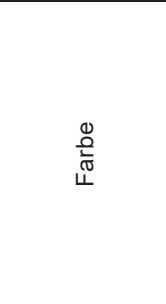 & 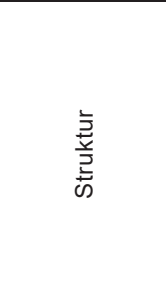 & 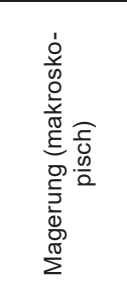 & 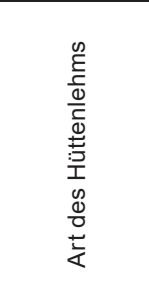 & 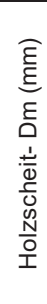 & 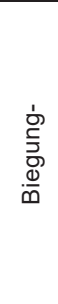 & 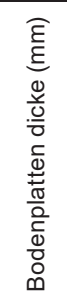 & 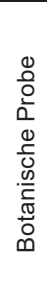 \\
\hline 174 & 433 & 4_6 & W-Mitte & $60-80 \mathrm{~cm}$ & 28 & beige-orange & kompakt & keine & Bodenplatte & & & & \\
\hline 177 & 433 & 4_6 & W-Mitte & $60-80 \mathrm{~cm}$ & 37 & beige-orange & kompakt & keine & Bodenplatte & & & & \\
\hline 178 & 433 & 4_6 & W-Mitte & $60-80 \mathrm{~cm}$ & 56 & beige-orange & kompakt & keine & Bodenplatte & & & & \\
\hline 180 & 433 & 4_6 & W-Mitte & $60-80 \mathrm{~cm}$ & 142 & beige-orange & kompakt & keine & Bodenplatte & & & & \\
\hline 187 & 433 & 4_6 & W-Mitte & $60-80 \mathrm{~cm}$ & 168 & $\begin{array}{c}\text { hellorange } \\
\text {-dunkelbraun }\end{array}$ & sehr kompakt & Glimmer & abgerundet & & 200 & & \\
\hline 188 & 433 & 4_6 & W-Mitte & $60-80 \mathrm{~cm}$ & 522 & $\begin{array}{l}\text { hellorange } \\
\text {-dunkelbraun }\end{array}$ & sehr kompakt & Glimmer & abgerundet & & & & \\
\hline 928 & 412 & 4_6 & W & $40-60 \mathrm{~cm}$ & 14 & hellorange & brüchig & organisch & flach & & & & \\
\hline 1008 & 401 & 4_6 & W & $50-55 \mathrm{~cm}$ & 19 & hellorange & brüchig & organisch & Keil & & & & \\
\hline 1559 & 433 & 4_6 & W-Mitte & $60-80 \mathrm{~cm}$ & 95 & $\begin{array}{c}\text { hellorange } \\
\text {-dunkelbraun }\end{array}$ & sehr kompakt & Glimmer & abgerundet & & 105 & & \\
\hline 1560 & 412 & 4_6 & W & $40-60 \mathrm{~cm}$ & 15 & hellorange & brüchig & Glimmer & flach & & & & \\
\hline 1561 & 433 & 4_6 & W-Mitte & $60-80 \mathrm{~cm}$ & 20 & hellorange & sehr kompakt & Glimmer & abgerundet & & 100 & & \\
\hline 1562 & 433 & 4_6 & W-Mitte & $60-80 \mathrm{~cm}$ & 31 & $\begin{array}{l}\text { hellorange- } \\
\text { dunkelbraun }\end{array}$ & sehr kompakt & Glimmer & flach & & & & \\
\hline 1563 & 420 & 4_6 & & $40-60 \mathrm{~cm}$ & 193 & beige-orange & kompakt & keine & Bodenplatte & & & 72 & \\
\hline 1565 & 427 & 4_6 & $\mathrm{N}$ & $60-70 \mathrm{~cm}$ & 118 & beige-orange & kompakt & keine & Bodenplatte & & & 45,5 & \\
\hline
\end{tabular}

Es wurden insgesamt 435 Hüttenlehmfragmente aus dem Befund 4/6 aufgenommen, mit einem Gesamtgewicht gleich 39,4 kg. Der Mittelwert aller Stücke ist gleich 90,78 g (Median $14 \mathrm{~g}$ ). Bei den sicheren Konstruktionselementen ist der Mittelwert des Gewichtes aller 310,6 g und der Median 83,5 g. Der Fragmentierungsgrad sowie die Lage des Hüttenlehms in dem Befund sprechen dafür, dass alle Fragmente in der Grube 4/6 absichtlich deponiert wurden und sollten nicht als Ergebnis eines nicht gerichteten, natürlichen Prozesses verstanden werden. Zwischen den Konstruktionshüttenlehmfragmenten machen drei Abdruckarten $96 \%$ der gesamten Kollektion aus (Abb. 4).

Zu der ersten Gruppe gehören keilförmige und beidseitig abgeflachte Fragmente, die sich höchstwahrscheinlich ursprünglich zwischen zwei breiten Rundhölzer oder Spaltholzbohlen befanden (Taf. III). Es lässt sich bereits makroskopisch eine organische Magerung beobachten, die für ein niedriges spezifisches Gewicht der Stücke, deren Masse einen Mittelwert von $50 \mathrm{~g}$ aufweist, verantwortlich ist (Abb. 5: a, b; vgl. Kapitel Archäobotanische Analysen; Tabelle 4). Bei meisten Fragmenten ist die Oberfläche zerstört und alle Seiten orange-rötlich oxidierend gebrannt (nach dem Munsell-Farbsystem 7,5YR 7/8, 5YR 7/8 und 5YR 6/8). Experimentalarchäologisch wurde nachgewiesen, dass der Hüttenlehm eine rötliche Farbe bei einer Brenntemperatur von $600-800{ }^{\circ} \mathrm{C}$ erreicht (Stevanović 1997, Tab. 4). Darüber hinaus beweisen die Beobachtungen des Abbrennens von Hausmodellen im Maßstab 1:1 in Freilichtmuseen, dass bei einem Brand hauptsächlich der Lehm aus den oberen Teilen des Gebäudes verziegelt und somit haltbar gemacht wird (Strutzberg 2006, 54).

Analoge Konstruktionsstücke sind sehr oft auf prähistorischen Fundstellen zu treffen, z. B. auf den spätbronzezeitlichen/früheisenzeitlichen Siedlungen in Maszkowice am oberen Dunajec, ${ }^{3}$ Grabowiec im Karpatenvorland (Baron/Karpow/Kużwik 2014, 58, Abb. 33: 13), Grzybiany in Unterschlesien (Baron/ Stolarczyk 2012, 109, Abb. 10: e, g, h) oder Roztoky in Mittelböhmen (Vařeka 2012, 109), wie auch auf der früheisenzeitlicher Siedlung in Bieganów in Großpolen (Narożna-Szamałek/Szamałek 2003, 59). Solche Fragmente werden allgemein als Verkleidung von Bohlen- und Blockbauwänden interpretiert (z. B. Půlpánová-Reszczyńska 2015, 194; Vařeka 2012, 109). Die organische Magerung spricht dafür, dass es sich um Wandelemente handelt (Půlpánová-Reszczyńska 2015, 194), die vielleicht im Fall der keilförmigen Fragmente von den Außenseiten stammen (Vařeka 2012,111).

\footnotetext{
3 Freundliche mündliche Mitteilung von Dr. habil. Marcin S. Przybyła.
} 
Die zweite Gruppe bilden an den Außenseiten abgerundete oder (nur in zwei Fällen) abgeflachte Fragmente, die sich durch ihre Magerung mit viel Glimmer, durch eine sehr kompakte Struktur (Mittelwert des Gewichts ist gleich $189 \mathrm{~g}$ ) und eine glatte, teilweise reduzierend gebrannte Oberfläche auszeichnen (Abb. 5: c, d; Taf. IV). Die oxidierend verbrannten Stellen hatten eine Farbe nach dem Munsell-Farbsystem gleich 10YR 6/6, 7,5YR 6/6 und 2,5Y 7/1; die reduzierend verbrannte Oberfläche ist gleich 5YR 2,5/1 und 2,5YR 5/1 und 4/1. Solche Farbtöne könnte der Rotlehm bei einer Temperatur von unter $400{ }^{\circ} \mathrm{C}$ bis ca. $600{ }^{\circ} \mathrm{C}$ für die oxiderend vebrannten Stellen und $900-1000{ }^{\circ} \mathrm{C}$ für die reduzierend verbrannten Stellen erreichen (Stevanović 1997, Tab. 4).

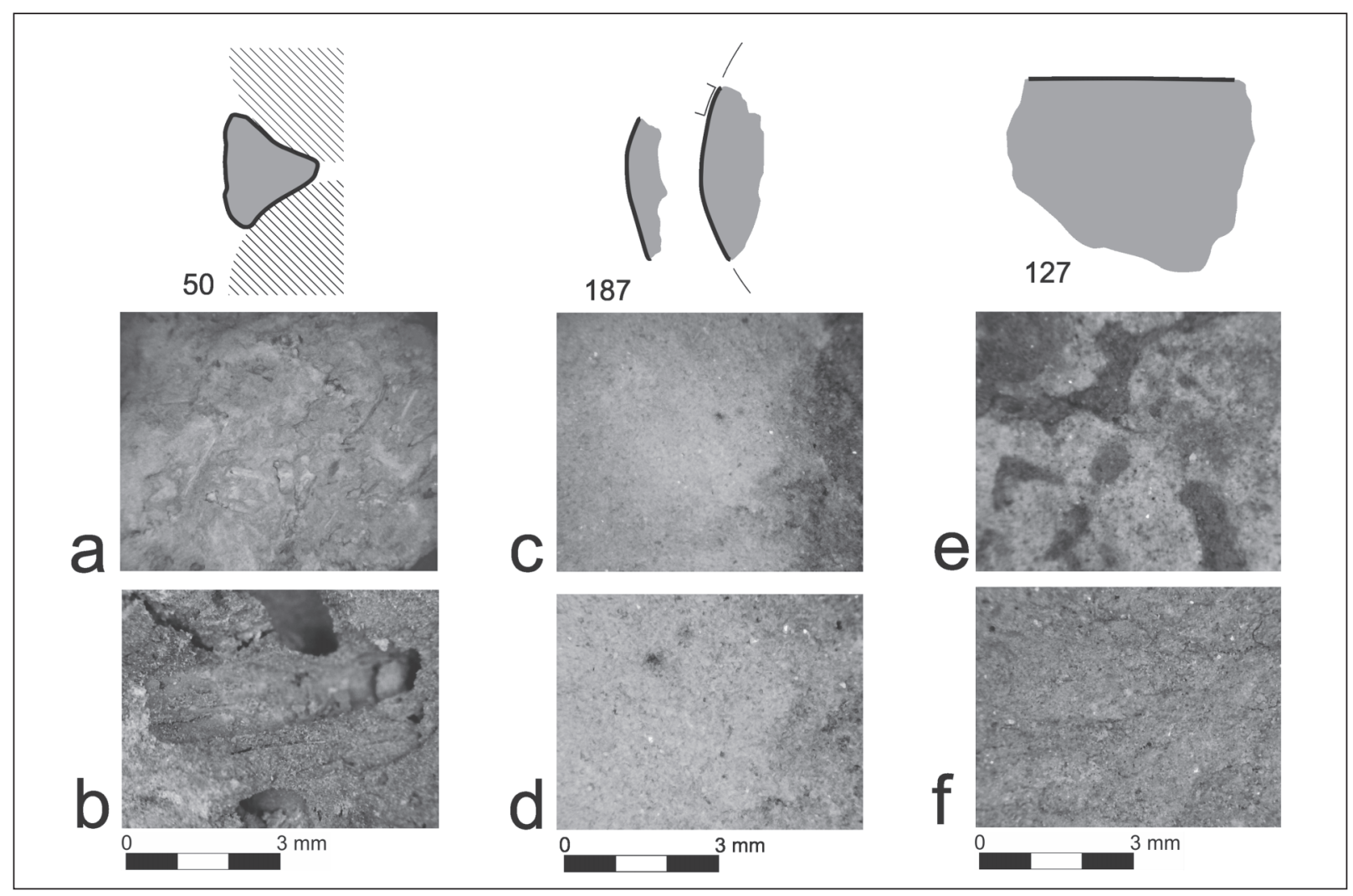

Abb. 5. Vergleich der Konstruktionshüttenlehmtechnologie der drei am häufigsten vorkommenden Formen im Befund $4 / 6$.

Analoge Stücke wurden in der spätbronzezeitlichen Verfüllung einer Abfallgrube auf der Siedlung in Öchlitz (Querfurter Platte im Sachsen-Anhalt) beobachtet (Knoll/Fröhlich 2017, 180, Abb. 15: 3). Es ist unklar, mit welchem Teil des Gebäudes solche Konstruktionselemente in Verbindung gebracht werden können. Die mineralogische Magerungskomponente spricht dort Franziska Knoll und Madeleine Fröhlich zufolge für die Nutzung im Bereich der Befeuerung einer Ofen- oder Herdeinrichtung (Knoll/ Fröhlich 2017, 180, vgl. auch Půlpánová-Reszczyńska 2015, 195). Auch die Beobachtung, dass wenigstens gewisse Teile der Fragmente eine hohe Temperatur erreicht haben, würde für diese Nutzungsmöglichkeit sprechen.

Die dritte Gruppe wird durch fast 36 extrem massive, einseitig abgeflachte Platten repräsentiert (Taf. V). Die Dicke der Fragmente, bei denen vermutlich die antiken Oberflächen überwiegend erhalten sind, reicht von ca. $7 \mathrm{~cm}$ bis $11 \mathrm{~cm}$ (Abb. 6) und das durchschnittliche Gewicht ist gleich 509 g. Bei all diesen Stücken konnten makroskopisch kaum Magerungsbestandteile beobachtet werden (Abb. 5: e, f; Tabelle 1; vgl. Kapitel Archäobotanische Analysen; Tabelle 4). Sobald die Oberfläche der flachen Oberseite erhalten war, hatten sie eine beige Farbe (nach Munsell-Farbsystem 10YR 7/2), die Richtung Unterseite ins Orange (nach Munsell-Farbsystem 5YR: 6/6 und 7/6 7,5 YR 6/6) überging. Experimente zeigen, dass bei optimalen oxidierenden Bedingungen von $900{ }^{\circ} \mathrm{C}$ der gesamte Kohlenstoff entfernt wird und der Lehm eine helle Farbe annimmt (Stevanović 1997, 366). Eine Temperatur zwischen $900-1000{ }^{\circ} \mathrm{C}$ führt zu den Farbtönen 7,5YR 7/2, 10R 6/1, 10YR: 7/1, 8/1, 8/4, 8/6 und 8/8 (Stevanović 1997, Tab. 4). Diesen Experimenten 
zufolge musste diese hohe Temperatur die Platten aus Janowice auf der abgeflachten Seite erreicht haben, während die „untere“ Seite mit einer Temperatur von $600-800^{\circ} \mathrm{C}$ verbrannt wurde. Ein diametrales Bild zeigen jedoch die Pläne von Häusern in der Siedlung in Smolnice-Molpír, wo die gesamten Fußbodenbereiche graugelb verfärbt sind, während die in den Häusern plazierte Feuerstellen rötliche Farbtöne haben (z. B. im Fall von Haus 1, s. Müller 2012, Abb. 16).

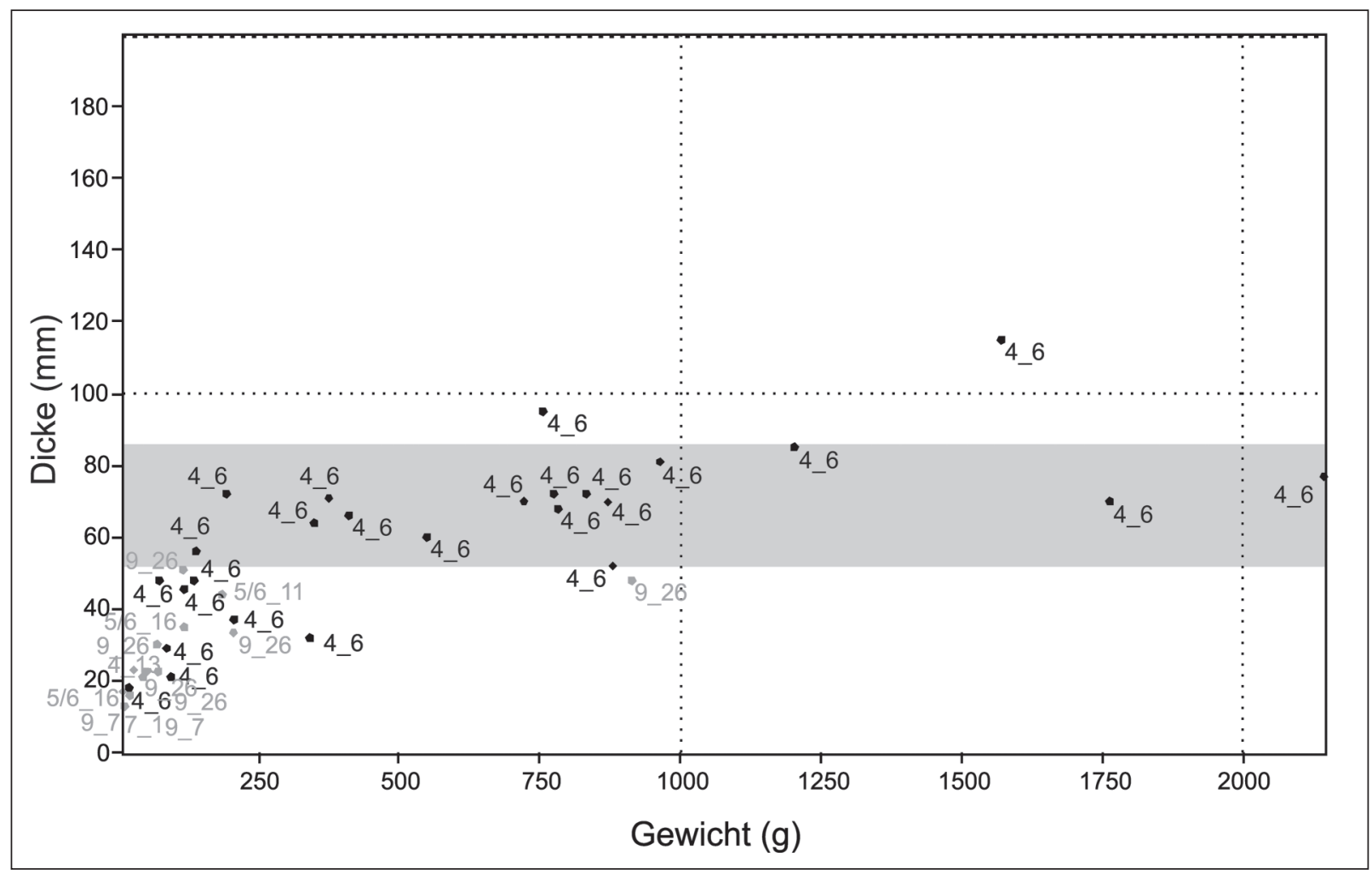

Abb. 6. Verteilung der Dicke aller plattenartigen Rotlehmfragmenten auf dem Siedlung in Janowice, Fdst. 6 (AZP 106$65 / 61)$.

Analoge Rotlehmfragmente wurden z. B. auf den Siedlungen in kleinpolnischen Modlnica ${ }^{4}$ und mittelböhmischen Roztoky (Vařeka 2012, 110) dokumentiert, bei der letztgenannten jedoch teilweise Spuren vom Ruß aufweisend. Nach P. Vařeka $(2012,110,111)$ könnte es sich dabei höchstwahrscheinlich um Teile eines Lehmbodens handeln. Auch auf mehreren früheisenzeitlichen Siedlungen aus Südwestdeutschland, der Ukraine und allgemein aus dem Hallstattkreis wurden ähnlich massive, kompakte Lehmplatten in situ entdeckt und als gestampfter Lehmboden, bzw. Herdeinrichtung interpretiert (vgl. Kapitel Interpretation des Befundes 4/6 - Szenario 3: Ein Haus mit Ofen und integrierter Darre).

Allgemein gesehen könnte also die Form des Hüttenlehms, die aus dem Befund 4/6 geborgen wurde, auf einen mutmaßlichen Fußboden und Wandversturz eines Hauses hindeuten, auch wenn es unsicher ist, um was für eine Struktur es sich handeln könnte (s. Kapitel Interpretation des Befundes 4/6).

\section{ARCHÄOBOTANISCHE ANALYSEN}

\section{Methoden}

Es wurden zwei Arten von botanischen Proben aus dem Befund 4/6 untersucht: Bodenproben und pflanzliche Abdrücke auf den Rotlehmfragmenten. Die entnommenen Bodenproben (Volumen von

\footnotetext{
4 Mündliche Information von Mgr. Karol Dzięgielewski.
} 
jeweils ca. 2-3 Liter) wurden auf Sieben mit einer Maschenweite von 0,2 und 0,5 mm geschlämmt. Aus den beiden Fraktionen wurden alle pflanzliche Überreste aussortiert, also Früchte, Samen, vegegatative Pflanzenteile, Hölzer und Wurzelknollen.

Es wurden auch sechs Hüttenlehmfragmente analysiert, in denen sowohl Pflanzenabdrücke, wie auch verkohlte und getrockene organische Pflanzenreste erhalten waren. Bei jedem Rotlehmfragment wurde erst die Oberfläche genau betrachtet und danach wurde er für weitere Analysen zerbrochen.

Tabelle 2. Janowice, Fdst. 6 (AZP 106-65/61), makroskopische Pflanzenreste aus den Bodenproben. Erhaltungzustand: v - verkohlt, uv - unverkohlt; Art der Reste: f - Frucht, s - Samen, k - Karyopsen, wk - Rhizome, sp - Speltze.

\begin{tabular}{|c|c|c|c|c|c|c|c|c|}
\hline $\begin{array}{l}\text { Schnitt_Be- } \\
\text { fund }\end{array}$ & $\begin{array}{c}\text { Tiefe } \\
\mathrm{cm}\end{array}$ & $\begin{array}{l}\text { Teil des } \\
\text { Befundes }\end{array}$ & $\begin{array}{c}\text { Inw. } \\
\text { Nummer }\end{array}$ & $\begin{array}{l}\text { Proben- } \\
\text { Nummer }\end{array}$ & Taxa & Art der Reste & $\begin{array}{l}\text { Erhaltungs- } \\
\text { zustand }\end{array}$ & Anzahl \\
\hline 4_6 & $60-80$ & $S$ & $83 / 08$ & 32 & Chenopodium album & $\mathrm{s}$ & uv & 35 \\
\hline $4 \_6$ & $60-80$ & $\mathrm{~S}$ & $83 / 08$ & 32 & Fallopia convolvulus & $f$ & uv & 3 \\
\hline 4_6 & $60-80$ & $\mathrm{~s}$ & $83 / 08$ & 32 & Polygonum sp. & $f$ & uv & 1 \\
\hline 4_6 & $60-80$ & SW & $56 / 08$ & 58 & Poaceae indet. & $\mathrm{k}$ & $\mathrm{v}$ & 4 \\
\hline 4_6 & $60-80$ & SW & $56 / 08$ & 58 & Chenopodium album & $\mathrm{s}$ & uv & 1 \\
\hline 4_6 & $60-80$ & NE & $32 / 08$ & 59 & Chenopodium album & $\mathrm{s}$ & uv & 9 \\
\hline $4 \_6$ & $60-80$ & $\mathrm{NE}$ & $32 / 08$ & 59 & Echinochloa crus-galli & $\mathrm{sp}$ & uv & 3 \\
\hline 4 4_6 & $60-80$ & $\mathrm{NE}$ & $32 / 08$ & 59 & Polygonum persicaria & $f$ & uv & 3 \\
\hline $4 \_6$ & $60-80$ & $\mathrm{NE}$ & $32 / 08$ & 59 & $\begin{array}{c}\text { Matricaria maritima } \\
\text { subsp. nodora }\end{array}$ & $f$ & uv & 1 \\
\hline 4 4_6 & $60-80$ & SE & $14 / 08$ & 60 & Chenopodium album & $\mathrm{s}$ & uv & 1 \\
\hline 4_6 & $60-80$ & SE & $14 / 08$ & 60 & unbestimmt & $?$ & uv & 3 \\
\hline $4 \_6$ & $40-60$ & W & $78 / 08$ & 81 & Hordeum vulgare & $\mathrm{k}$ & $\mathrm{v}$ & 1 \\
\hline 4_6 & $40-60$ & W & $78 / 08$ & 81 & Cerealia indet. & $\mathrm{k}$ & $\mathrm{v}$ & 3 \\
\hline 4_6 & $40-60$ & W & $78 / 08$ & 81 & Pisum sativum & $\mathrm{s}$ & $\mathrm{v}$ & 1 \\
\hline 4 4_6 & $40-60$ & W & $78 / 08$ & 81 & Chenopodium album & $\mathrm{s}$ & uv & 12 \\
\hline 4_6 & $40-60$ & W & $78 / 08$ & 81 & Polygonum aviculare & $f$ & uv & 1 \\
\hline $4 \_6$ & $40-60$ & W & $78 / 08$ & 81 & Polygonum minus & $f$ & uv & 1 \\
\hline 4 4_6 & $40-60$ & W & $78 / 08$ & 81 & Polygonum persicaria & $f$ & uv & 1 \\
\hline 4 4_6 & $40-60$ & W & $78 / 08$ & 81 & Polygonum sp. & $f$ & uv & 1 \\
\hline 4 4_6 & $40-60$ & W & $78 / 08$ & 81 & Equisetum sp. & wk & uv & 1 \\
\hline
\end{tabular}

Die Bestimmung der pflanzlichen Überresten wurde anhand eines in archäobotanischen Studien gängigen Verfahrens durchgeführt (Lityńska-Zają/Wasylikowa 2005, 182-190, dort weitere Literatur). Die Benennung der Pflanzen wurde der heutigen botanischen Nomenklatur übernommen (Mirek u. a. 2002). Die Ergebnisse der botanischen Analyse sind in den Tabellen 2-5 dargestellt.

\section{Ergebnisse den Bodenprobenanalysen}

Es wurden sechs Proben aus der Verfüllung der Grube 4/6 untersucht. In einer der Proben (Probeninventar-Nummer 35) wurden nur Holzkohlefragmente und sehr kleine Rotlehmfragmente (Durchmesser gleich $0,5 \mathrm{~mm}$ ) mit schwach sichtbarer organischer Magerung beobachtet. Weitere fünf Bodenproben haben nicht viele pflanzliche Überreste beinhaltet - insgesamt 85 (Tabelle 2). Es wurden 12 Taxa bestimmt, darunter neun bis auf Speziesniveau. Getreideüberreste betreffend wurde eine Gerste-Karyopse Hordeum vulgare und unbestimmte Exemplare von Cerealia indet. registriert. Leguminosen wurden durch einen Samen der Speiseerbse Pisum sativum repräsentiert. Das opulentestes Überrestenensemble wurde in der Probe 81 beobachtet. In den untersuchten Materialien wurden auch Knollen von dem Rhizom von Schachtelhalm Equisetum sp. beobachtet. Drei Frucht- und/oder Samenfragmenten wurde keine taxonomische Zugehörigkeit zugewiesen.

Ein Teil den Diasporen hat sich in einem unverkohlten Zustand erhalten (Tabelle 2). Sie können wohl als eine Verunreinigung durch ein jüngeres Material interpretiert werden und stehen nicht im archäologischen Kontext. Die besprochene Fundstelle befindet sich außerhalb des Grundwasserbereiches, welcher ggfs. die Erhaltung solcher Exemplaren ermöglicht hätte. Zwischen den unverkohlten Propagulen kommen am häufigsten die Samen des Weißen Gänsefuß Chenopodium album vor.

Unter den Holzfragmenten wurde sechs Baumetaxa bis auf Spezies und Gattung unterschieden: Tanne (Abies alba), Hainbuche (Carpinus betulus), Buche (Fagus sylvatica), Ahorn (Acer sp.), Birke (Betula 
sp.), Eiche (Quercus sp.; Abb. 7; Tabelle 3). Am häufigsten kamen Überreste von Eiche, Hainbuche und Buche vor (Abb. 8). Die größte taxonomische Vielfallt wurde im SO-Teil des Befundes beobachtet, also außerhalb der kreisrunden Struktur mit Konstruktionshüttenlehm. Niedrige taxonomische Differenzierung könnte darauf hinweisen, dass die Holzkohle aus der Grube 4/6 von verbrannten Konstruktionselementen stammen könnte (alle drei am häufigstens überlieferten Holzarten sind durch besondere Härte gekennzeichnet). Andererseits könnte es sich dabei auch um Brennholz handeln (vgl. Interpretation des Eichenholzes aus den Verfüllungsschichten des Ofens aus Hrubiszów; Dzięgielewwski 2013, 27; s. auch Kapitel Interpretation des Befundes 4/6 - Szenario 1: Ein Haus mit einem Grubenofen). Außerdem kann das Vorkommen von drei weiteren Holztaxa dafür sprechen, dass es sich allgemein um einen heterogenen Komplex handelt. Es ist bemerkenswert, dass in den anderen Gruben in Janowice zwar insgesamt 21 Taxa entdeckt wurden (Moskal-del Hoyo u. a. 2015; Moskal-del Hoyo, unpubliziert), aber auch dort gehören Eiche, Buche und Hainbuche zu den am häufigstens vorkommenen Arten.

Tabelle 3. Janowice, Fdst. 6 (AZP 106-65/61), Holzkohle aus den Bodenproben. Erhaltungzustand: v - verkohlt; Art der Reste: $\mathrm{h}$ - Holzkohle.

\begin{tabular}{|c|c|c|c|c|c|c|c|}
\hline Schnitt_Befund & Tiefe & $\begin{array}{l}\text { Teil des } \\
\text { Befundes }\end{array}$ & Inv.-Nummer & Taxa & $\begin{array}{l}\text { Art des Über- } \\
\text { restes }\end{array}$ & $\begin{array}{l}\text { Erhaltung- } \\
\text { zustand }\end{array}$ & Anzahl \\
\hline 4_6 & $60-80$ & SE & 60 & Quercus sp. & $\mathrm{h}$ & $\mathrm{v}$ & 21 \\
\hline 4_6 & $60-80$ & SE & 60 & Fagus sylvatica & $\mathrm{h}$ & $\mathrm{v}$ & 12 \\
\hline 4_6 & $60-80$ & SE & 60 & Betula sp. & $\mathrm{h}$ & v & 1 \\
\hline 4_6 & $60-80$ & SE & 60 & Acer sp. & $\mathrm{h}$ & $\mathrm{v}$ & 1 \\
\hline 4_6 & $60-80$ & SE & 60 & Abies alba & $\mathrm{h}$ & v & 1 \\
\hline 4_6 & $60-80$ & SE & 60 & Nadelbäume & $\mathrm{h}$ & v & 1 \\
\hline 4_6 & $60-80$ & SE & 60 & Laubbäume & $\mathrm{h}$ & $\mathrm{v}$ & 1 \\
\hline 4_6 & $60-80$ & SE & 60 & Carpinus betulus & $\mathrm{h}$ & v & 2 \\
\hline 4_6 & $60-80$ & SE & 60 & unbestimmt & $\mathrm{h}$ & $\mathrm{v}$ & 1 \\
\hline 4_6 & $40-60$ & W & 81 & Quercus sp. & $\mathrm{h}$ & $\mathrm{v}$ & 20 \\
\hline 4_6 & $40-60$ & W & 81 & Fagus sylvatica & $\mathrm{h}$ & v & 17 \\
\hline 4_6 & $40-60$ & W & 81 & Carpinus betulus & $\mathrm{h}$ & $\mathrm{v}$ & 3 \\
\hline 4_6 & $60-80$ & $S$ & 32 & Quercus sp. & $\mathrm{h}$ & $\mathrm{v}$ & 11 \\
\hline 4_6 & $60-80$ & $S$ & 32 & Fagus sylvatica & $\mathrm{h}$ & v & 17 \\
\hline 4_6 & $60-80$ & $S$ & 32 & Carpinus betulus & $\mathrm{h}$ & $\mathrm{v}$ & 10 \\
\hline 4_6 & $60-80$ & $\mathrm{~S}$ & 32 & Laubbäume & $\mathrm{h}$ & $\mathrm{v}$ & 1 \\
\hline 4_6 & $60-80$ & $\mathrm{NE}$ & 59 & Fagus sylvatica & $\mathrm{h}$ & $\mathrm{v}$ & 29 \\
\hline 4_6 & $60-80$ & $\mathrm{NE}$ & 59 & Quercus sp. & $\mathrm{h}$ & $\mathrm{v}$ & 6 \\
\hline 4_6 & $60-80$ & NE & 59 & Carpinus betulus & $\mathrm{h}$ & $\mathrm{v}$ & 5 \\
\hline 4_6 & $60-80$ & $\mathrm{NE}$ & 59 & unbestimmt & $\mathrm{h}$ & $\mathrm{v}$ & 3 \\
\hline 4_6 & $60-80$ & SW & 58 & Fagus sylvatica & $\mathrm{h}$ & v & 19 \\
\hline 4_6 & $60-80$ & SW & 58 & Quercus sp. & $\mathrm{h}$ & $\mathrm{v}$ & 10 \\
\hline 4_6 & $60-80$ & SW & 58 & Laubbäume & $\mathrm{h}$ & $\mathrm{v}$ & 1 \\
\hline 4_6 & $60-80$ & SW & 58 & unbestimmt & $\mathrm{h}$ & $\mathrm{v}$ & 1 \\
\hline 4_6 & $60-80$ & NW & 35 & Fagus sylvatica & $\mathrm{h}$ & $\mathrm{v}$ & 19 \\
\hline 4_6 & $60-80$ & NW & 35 & Quercus sp. & $\mathrm{h}$ & $\mathrm{v}$ & 16 \\
\hline 4_6 & $60-80$ & NW & 35 & Acer sp. & $\mathrm{h}$ & v & 5 \\
\hline
\end{tabular}

\section{Ergebnisse der Konstruktionsrotlehmanalyse}

Die Untersuchungen der pflanzlichen Abdrücke im Rotlehm weisen einen ergänzenden Charakter zu den Bodenprobenanalysen auf. Dies ist ein Resultat der Tatsache, dass "diese Art von pflanzlichen Materialien selektive Informationen bringt; es wurden nämlich solche Pflanzen vorgezogen, deren abgedrückte Organe eine relative Größe und ein spezifisches Oberflächerelief zeigen, während andere, besonders kleine glatte Diasporen der krautigen Pflanzen eliminiert wurden" (Lityńska-Zajac/Wasylikowa 2005, 296). Nichtsdestotrotz spielen sie eine besondere informative Rolle bezüglich der Spezies, die als Magerung des Rotlehms verwendet wurden (Moskal-del Hoyo u. a. 2017, dort weitere Literatur) und/oder für die Konstruktionselemente der Gebäude.

Die analysierten Rotlehmfragmente waren von unterschiedlicher Größe und gehörten zu den drei oben beschriebenen Gruppen. 
EIG'NER HERD IST GOLDES WERT

Tabelle 4. Janowice, Fdst.6 (AZP 106-65/61), Pflanzenabdrücke in Hüttenlehm. Erhaltungzustand: v - verkohlt, a - Abdruck, g - getrocknet; Art der Reste: k - Karyopsen, ag - Ährchengabel, sp - Speltze, h - Holz, bl - Blatt, ha - Stroh.

\begin{tabular}{|c|c|c|c|c|c|c|c|c|c|c|}
\hline $\begin{array}{l}\text { Schnitt_ } \\
\text { Befund }\end{array}$ & $\begin{array}{c}\text { Anzahl } \\
\text { der } \\
\text { Klumpen }\end{array}$ & $\begin{array}{l}\text { Tiefe } \\
\mathrm{cm}\end{array}$ & $\begin{array}{l}\text { Proben- } \\
\text { Nummer }\end{array}$ & $\begin{array}{c}\text { Art des } \\
\text { Hüttenlehms }\end{array}$ & $\begin{array}{l}\text { Gewicht } \\
\text { (g) }\end{array}$ & Taxa & $\begin{array}{l}\text { Art der } \\
\text { Reste }\end{array}$ & $\begin{array}{l}\text { Erhaltungs } \\
\text { zustand }\end{array}$ & Anzahl & Beschreibung \\
\hline $4 \_6$ & 2 & $60-80$ & B-5 & Bodenplatte & \multirow{6}{*}{2756} & unbestimmt & $\mathrm{h}$ & a & mehrere & $\begin{array}{l}\text { Konstruktion- } \\
\text { sabdrücke }\end{array}$ \\
\hline 4_6 & 2 & $60-80$ & B-5 & Bodenplatte & & Quercus sp. & $\mathrm{h}$ & v & 1 & Holzkohle \\
\hline 4_6 & 2 & $60-80$ & B-5 & Bodenplatte & & unbestimmt & $\mathrm{h}$ & v & 4 & Holzkohle \\
\hline 4_6 & 2 & $60-80$ & B-5 & Bodenplatte & & Cerealia indet. & ha & $\mathrm{a}$ & 4 & \\
\hline 4_6 & 2 & $60-80$ & B-5 & Bodenplatte & & Cerealia indet. & ha & V & 1 & \\
\hline 4_6 & 2 & $60-80$ & B-5 & Bodenplatte & & Cerealia indet. & $\mathrm{k}$ & a & 2 & \\
\hline 4_6 & 1 & $40-60$ & B-19 & Rundhölzer & \multirow{4}{*}{52} & Triticum dicoccon vel T. monococcum & $\mathrm{k}$ & a & 3 & \\
\hline 4 4_6 & 1 & $40-60$ & B-19 & Rundhölzer & & Triticum dicoccon vel T. monococcum & ag & $\mathrm{v}$ & 2 & im Fragment \\
\hline 4_6 & 1 & $40-60$ & B-19 & Rundhölzer & & Triticum dicoccon vel T. monococcum & $\mathrm{sp}$ & v & 6 & im Fragment \\
\hline 4_6 & 1 & $40-60$ & B-19 & Rundhölzer & & Cerealia indet. & ha & $\mathrm{v}$ & 21 & im Fragment \\
\hline 4_6 & 1 & $40-60$ & B-20 & Rundhölzer & \multirow{4}{*}{32} & Hordeum vulgare & $\mathrm{k}$ & $\mathrm{a}$ & 1 & \\
\hline 4_6 & 1 & $40-60$ & $\mathrm{~B}-20$ & Rundhölzer & & Triticum dicoccon vel T. monococcum & $\mathrm{k}$ & a & 7 & \\
\hline 4 4_6 & 1 & $40-60$ & B-20 & Rundhölzer & & Triticum dicoccon vel T. monococcum & ag & $\mathrm{g}$ & 2 & im Fragment \\
\hline 4_6 & 1 & $40-60$ & B-20 & Rundhölzer & & Cerealia indet. & ha & v & mehrere & im Fragment \\
\hline 4 4_6 & 1 & $50-55$ & B-21 & Flachhölzer & \multirow{4}{*}{25} & Poaceae indet. & $\mathrm{k}$ & $\mathrm{a}$ & 2 & \\
\hline 4_6 & 1 & $50-55$ & B-21 & Flachhölzer & & Cerealia indet. & ha & v & mehrere & im Fragment \\
\hline 4_6 & 1 & $50-55$ & $\mathrm{~B}-21$ & Flachhölzer & & Triticum dicoccon vel T. monococcum & $\mathrm{k}$ & a & 2 & \\
\hline 4_6 & 1 & $50-55$ & B-21 & Flachhölzer & & Triticum dicoccon vel T. monococcum & ag & $\mathrm{v}$ & 5 & \\
\hline 4_6 & 1 & $40-60$ & B-18 & Flachhölzer & \multirow{4}{*}{27} & Cerealia indet. & $\mathrm{k}$ & a & mehrere & \\
\hline 4_6 & 1 & $40-60$ & B-18 & Flachhölzer & & Cerealia indet. & ha & a & mehrere & \\
\hline 4_6 & 1 & $40-60$ & B-18 & Flachhölzer & & Cerealia indet. & ha & v & mehrere & \\
\hline 4 4_6 & 1 & $40-60$ & B-18 & Flachhölzer & & Dicotyledones & bl? & $a$ & 1 & \\
\hline
\end{tabular}

Zwei Fragmente aus der dritten Hüttenlehmgruppe waren sehr kleinkörnig und relativ gut gebrannt (Tabelle 1: ID-Nummer 7, 8). Die Farbe innen war Orange. Auf der unteren Oberfläche wurden Konstruktionsabdrücke beobachtet, die von Spaltbohlenhölzer stammen könnten. Die Spuren von krautigen Pflanzen, sowohl wilden wie auch gezüchteten und deren verkohlte Überreste waren in beiden Fragmenten chaotisch verteilt. In den verbrannten Stücken wurde auch Holzkohle festgestellt, in den meisten Fällen unbestimmt, aber ein Fragment wird als Eiche Quercus sp. identifiziert (Tabelle 4; 5). Die Form der besprochenen Hüttenlehmfragmente spricht dafür, dass es sich um Fussbodenelemente handeln könnte (vgl. Kapitel Hüttenlehm und Kapitel Interpretation des Befundes 4/6).

Tabelle 5. Janowice, Fdst. 6 (AZP 106-65/61), makroskopische Pflanzenreste aus dem Befund 4/6, die auf spätbrozezeitliches/früheisenzeitliches Horizont zu datieren sind. Erklärungen, Abkürzungen wie in den Tabellen 1; 2.

\begin{tabular}{|c|c|c|c|c|}
\hline \multirow{2}{*}{ Taxe } & \multirow{2}{*}{ Art der Reste } & \multirow{2}{*}{$\begin{array}{c}\text { Bodenprobe } \\
\text { v }\end{array}$} & \multicolumn{2}{|c|}{ Hüttenlehm } \\
\hline & & & a & $\mathbf{v}$ und $\mathbf{g}$ \\
\hline Hordeum vulgare & $\mathrm{k}$ & 1 & 1 & \\
\hline Triticum dicoccon vel T. monococcum & k & & 3 & \\
\hline Triticum dicoccon vel T. monococcum & ag & & & 3 \\
\hline Cerealia indet. & $\mathrm{k}$ & 3 & 2 & \\
\hline Cerealia indet. & ha & & 2 & 5 \\
\hline Pisum sativum & $\mathrm{s}$ & 1 & & \\
\hline Poaceae indet. & $\mathrm{k}$ & 4 & 1 & \\
\hline Quercus sp. & ha & & & 1 \\
\hline Dicotyledones & bl & & 1 & \\
\hline
\end{tabular}




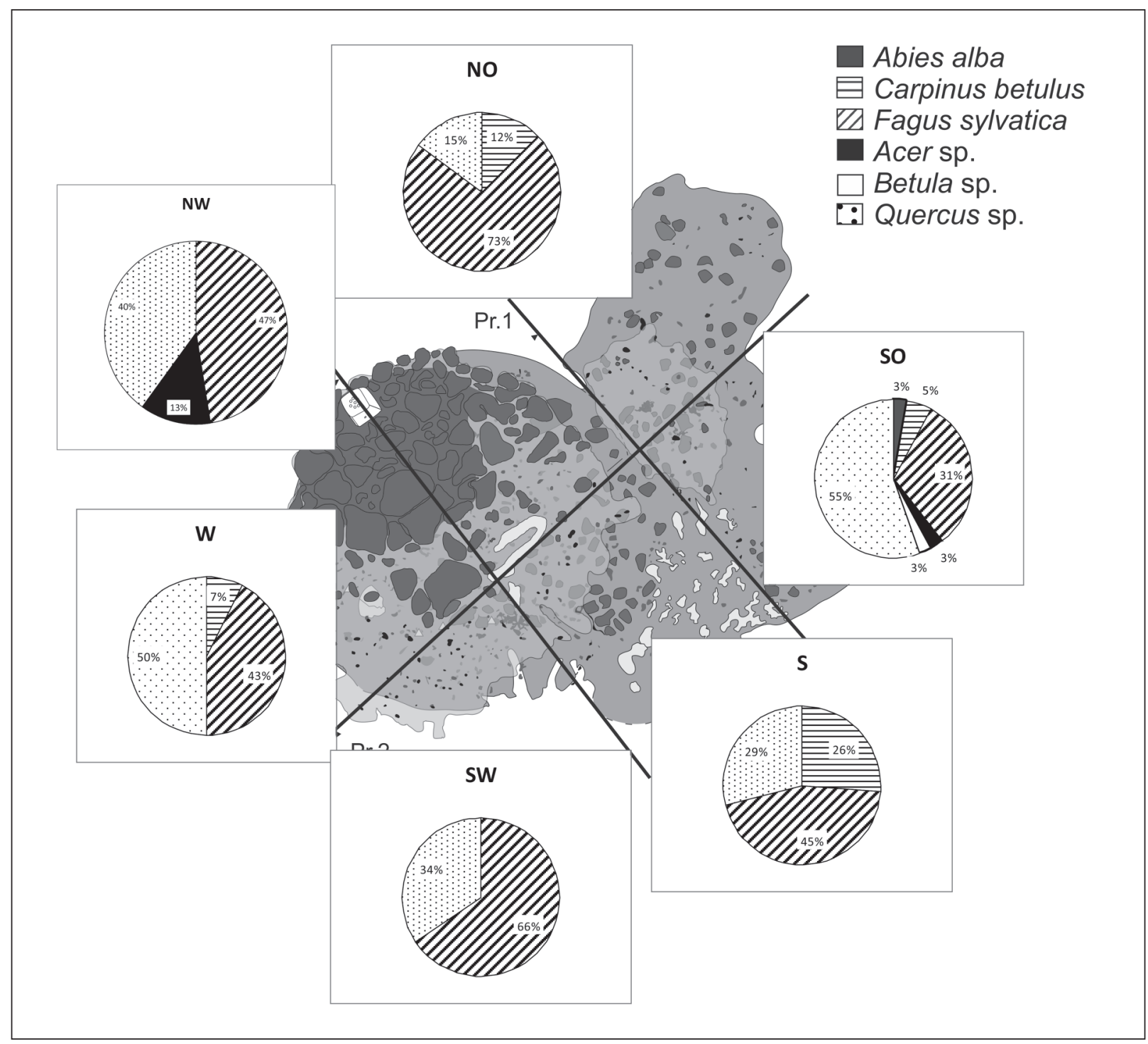

Abb. 7. Resultat der anthrakologischen Analyse und räumliche Verteilung der Bodenproben in dem Befund 4/6.

Vier weitere Fragmente - Beispiele des Rotlehms der ersten Gruppe - waren deutlich kleiner und wie bereits erwähnt, könnten sie von den Wänden stammen (vgl. Kapitel Hüttenlehm und Kapitel Interpretation des Befundes 4/6 - Szenario 1: Ein Wohnhaus; Tabelle 1: ID-Nummer 34, 40, 42 und 58). Sie waren brüchiger und scheinen stärker verbrannt zu sein (?), als die Stücke der ID-Nummern 7 und 8. In den analysierten Fragmenten wurden negative und positive Abdrücke von Karyopsen von Emmer und/oder Einkorn Triticum dicoccon vel T. monococcum, sowie Fragmente von Spreu (Ährchengabel und Spelzen), Samenhüllen und Stängelteile beobachtet. Die letztgenannten Exemplare hatten eine graue Farbe und sind in der Form von sehr zarten "seidenpapierartigen Beläge“ aufgetreten. In einem flachen Fragment von einer Dicke gleich $5 \mathrm{~cm}$ und von einer inneren schwarzen Seite (Tabelle 1: ID-Nummer 34) sind verkohlte Fragmente von Getreidestroh Cerealia indet. erhalten geblieben. Darüberhinaus war auf der Oberfläche ein Abdruck der Mittelader und der sekundären Adern ersten Grades eines Blattes von unklarem Umriss sichtbar. Höchstwahrscheinlich handelt es sich dabei um ein Fragment eines mittleren Blattspreitsteils einer näher unbestimmbaren zweikeimblättrigen Pflanze (Dicotyledones).

In Befund 4/6 wurde außer unbestimmten Getreideteilen Cerealia indet. eine vereinzelte Karyopse der Gerste Hordeum vulgare sowie Abdrücke von Karyopsen und Ähren von einer oder zwei Weizenspezies (Triticum dicoccon vel T. monococcum) entdeckt. Die gerade erwähnten Pflanzensorten wurden auch in anderen Befunden der Siedlung in Janowice, Fdst. 6 beobachtet (Lityńska-Zajac/Moskal-del Hoyo/Cywa 2014; Lityńska-Zajac u. a. 2017; Moskal-del Hoyo u. a. 2015), was auf lokalen Anbau des Getreides schlie- 


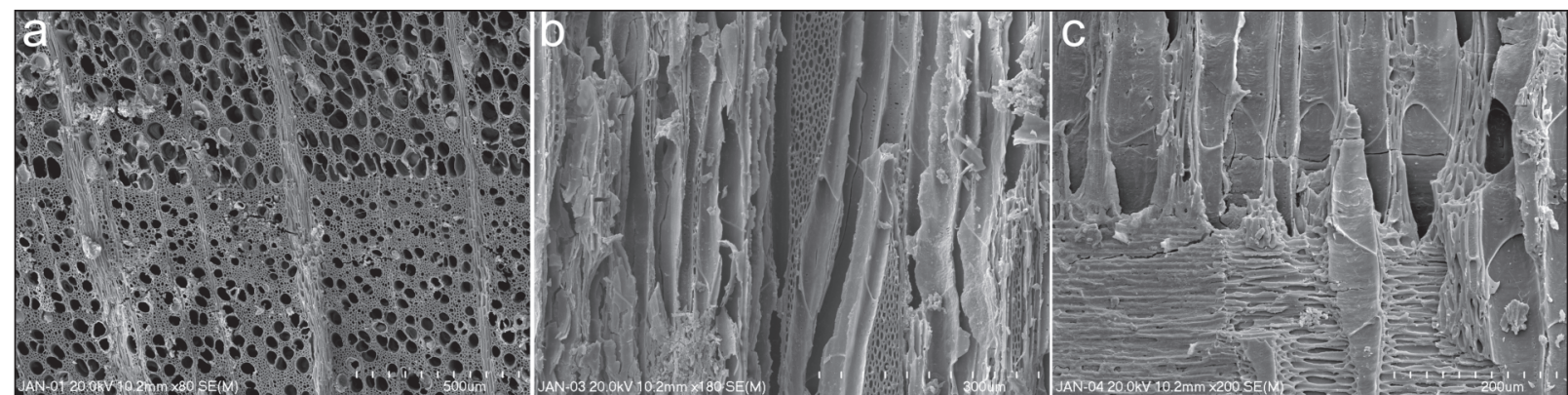

Abb. 8. Ein Beispiel eines Holzkohlefragmentes von Fagus sylvatica aus dem Befund 4/6 (Probennummer 32) in anathomischen Querschnitten. a - Querschnittfläche; b - tangentiale Schnittfläch; c - radiale Schnittfläche.

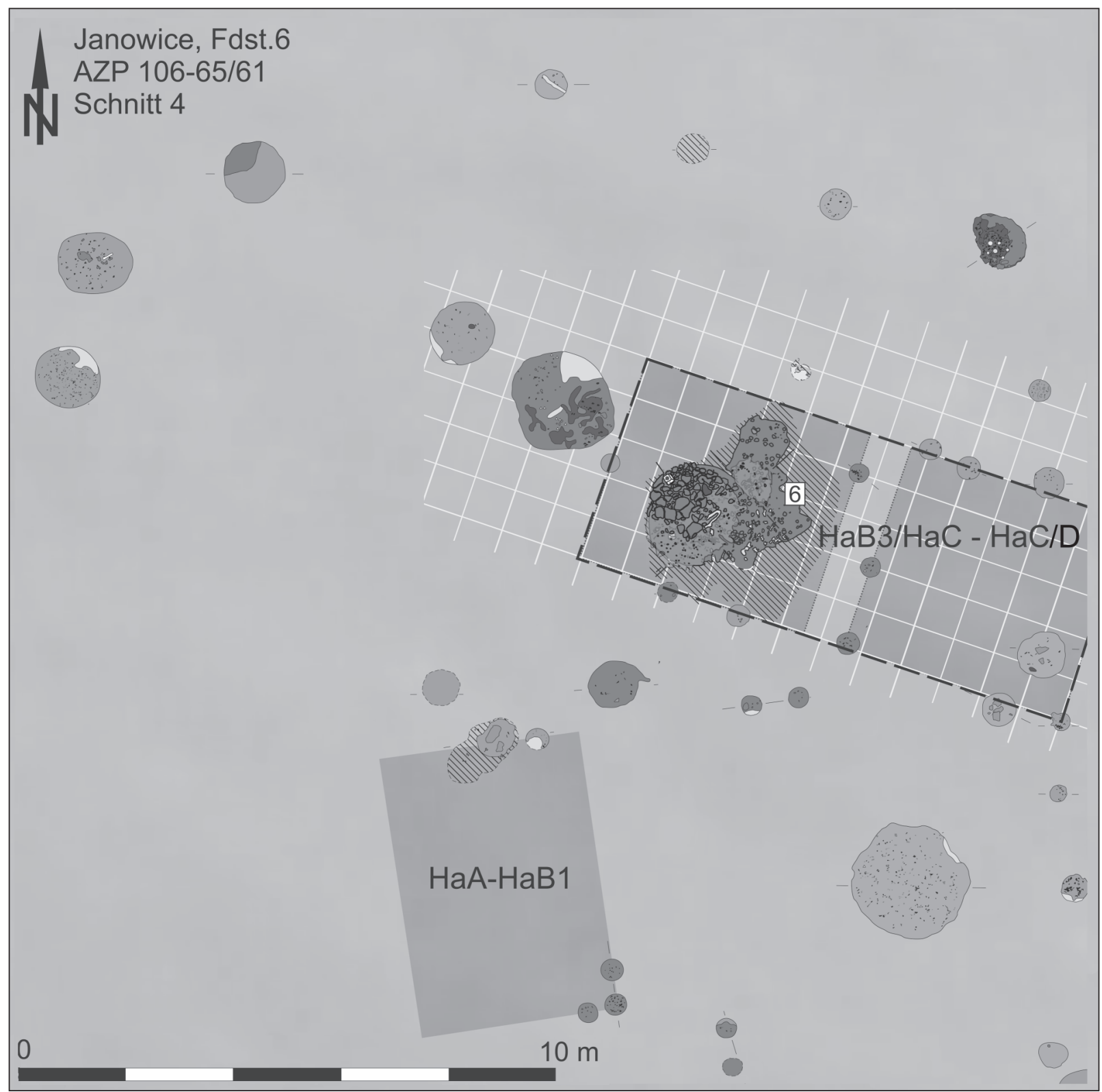

Abb. 9. Rekonstruktionsvorschlag des früheisenzeitlichen Wohnhauses des früheisenzeitliches Wohnhauses um die Grube 4/6 herum. 
ßen lässt. Viele der krautigen Pflanzen sind repräsentiert durch unbestimmte Karyopsen von Gräsern (Poaceae indet.).

Basierend auf den in den Hüttenlehmfragmenten erhaltenen Materialien können wir sagen, dass dem Konstruktionslehm eine organische Magerung beigemischt wurde; diese bestand aus Ährenfragmenten und kleinen und größeren Fragmenten von Getreidehalmen, die von den Trägern der Lausitzer Kultur angebaut wurden - also vor allem Einkorn und/oder Emmer und darüberhinaus wilde Gräser (Tabelle 4; 5). Die Benutzung von pflanzlichen Materialien hat die Elastizität des Substrats erhöht, die Ausbildung von Rissen verhindert und sie hat die Rotlehmmasse widerstandsfähiger gegen sonstige Umwelteinflüsse gemacht.

Eichenholz, welches in einem der Fragmente erhalten blieb, suggeriert die Benutzung dieser Holzart zu Konstruktionszwecken. Eichenholz taugt sehr gut als Bausubstanz. Beide Gattungen, die in unserer Flora sehr oft vorkommen, also Stieleiche (Quercus robur) und Traubeneiche (Quercus petraea), haben Holz mit ähnlichen Eigenschaften. Das Holz hat gerade Fasern, ist ziemlich schwer und schrumpft nur mittelmäßig; es lässt sich gut spalten und somit ziemlich gut bearbeiten. Es ist nur schwer entzündlich, verfügt über gute Isolationseigenschaften und weist gute Haltbarkeit auf (Podbielkowski 1985; Tomanek 1987, 268, 270; Warywoda 1957).

\section{INTERPRETATION DES BEFUNDES 4/6}

\section{Ein Wohnhaus}

Ob es sich bei dem Hüttenlehm der Gruppe 1 um Konstruktionselemente eines Hauses mit Bohlenwänden oder - weniger wahrscheinlich - um Teile eines Hauses in Blockbauweise handelte, kann allein anhand der Rotlehmformen wegen ihres starken Fragmentierungsgrades nicht eindeutig gesagt werden. Die keilförmigen Fragmente vom Fugenstrich mit zwei konkaven Innenflächen könnten theoretisch von einem Haus, das im Blockbautechnik gebaut wurde, stammen; diese Konstruktion hängt aber sehr eng mit dem Vorhandensein von Nadelhölzern zusammen (die Bohlen für die Wände mussten gerade und von gleicher Dicke sein, was bei einer Eiche nur durch die Spaltung und Nachbearbeitung der Stämme erreicht werden kann; s. Zimmermann 1998, 77, Abb. 44). Die aus Eichenholz konstruierten Brunnen aus Sachsen, darunter z. B. frühneolithische Befunde aus Droßdorf (Kretschmer u. a. 2016, 37-44), oder jungstein-, bronze- und eisenzeitliche Brunnen aus Zwenkau (Stäuble/Campen 1998, Abb. 3) scheinen eine Ausnahme zu bilden. Belegt ist, dass Eichenholz in der Neuzeit für Blockbauten nur in Notfällen verwendet wurde (Zimmermann 1998, 77). Da kaum verbrannte Nadelhölzer in den Bodenproben aus dem Befund 4/6 nachgewiesen wurden und zugleich mehrere die Grube umgebende Pfosten gefunden wurden, scheint es wahrscheinlicher, dass es sich um eine andere Konstruktionsart handelt. Es ist zwar unsicher, ob die Pfosten zu der Grube 4/6 zeitgleich sind, mehrere davon scheinen jedoch in Flucht zu liegen, was darauf hindeuten würde. T. Gralak (2013) hat in seinen Studien zu Hausstrukturen auf Ha C-zeitlichen Siedlungen in Schlesien beobachtet, dass sich auf den von ihm analysierten Siedlungen (z. B. in Wojkowice 15 - Gralak 2013, Abb. 2; Milejowice 19 - Gralak 2013, Abb. 3-4; oder Stary Śleszów 17 Gralak 2013, Abb. 5) der Abstand zwischen den Pfosten im Rahmen einer möglichen Wohnstruktur in ein Raster von 0,785 m Maschenweite fügen lässt. Interessanterweise können auch die Pfosten in Janowice in ein Gitter von einer Maschenweite gleich 0,785 m eingefügt werden. Der auf der Abb. 9 vorgeschlagene Plan eines Wohnhauses mit einer westlich benachbarten Vorratsgrube (?), ${ }_{1}^{5}$ der aus zwei gleichen Modulen/Teilen bestehen könnte, sollte jedoch nur als eine von mehreren Rekonstruktionsmöglichkeiten verstanden werden. Die Abwesenheit von manchen Pfosten (v.a. im NW-Teil des Areals) könnte mit der starken Hangerosion zusammenhängen - der Schnitt liegt auf einem Hang der in Nordwest Richtung ansteigt. Vielleicht ist also das aus Eichen-, evtl. Hainbuchen- und/oder Buchenhölzern gebaute Haus aus Janowice ein Beispiel kombinierte Bauform von Pfosten- und für eine Ständerkonstruktion, wie es z. B. im Fall des spätneolithischen Gebäudes auf der Flur Langenkamp in Flintbek (nach Zimmermann 1998, 83) nachgewiesen wurde. In dem Zusammenhang ist es bemerkenswert, dass in den kleinen, flachen, wannenförmigen Gruben im SO-Teil des Areals mehrere verbrannte, flache Sandsteinplatten gefunden wurden, die eventuell aus den teilweise zerstörten, aber in dem Bereich noch erhaltenen Lagersteinfun-

\footnotetext{
5 Zwar ist die im Profil trapezförmige Grube 4/13 nicht besonders tief (ca. $35 \mathrm{~cm}$ ), analoge Tiefen haben aber auch andere Gruben aus dem NW-Bereich des Schnittes 4, was als Resultat einer starker Erosion interpretiert werden könnte.
} 
damenten stammen könnten. Die Kombination von unterschiedlichen Holzarten bei der Ständerkonstruktion ist z. B. auf dem Ha C-zeitlichen Burgwall in Biskupin anzutreffen, wo die runden Bohlenständer ausschließlich aus Tannenhölzer konstruiert waren, während die eckigen Spaltholzbohlenständer aus Eichenholz gefertigt wurden (Rajewski 1950, 264).

\section{Szenario 1: Ein Haus mit einem Grubenofen}

Die kompakte Verteilung des Hüttenlehms im nördlicher Teil der Grube 4/6 und die wannenförmige Form des Befundes erinnern an eine zusammengebrochene Ofeninstallation, die u. a. auf den Fundstellen in Hrubieszów (Dzieggielewski 2013), Poznań-Sołacz (Michalski 1983) oder Modlniczka $2^{6}$ dokumentiert wurde. Sowohl der Ofen aus Hrubiszów, wie auch der Befund aus Poznań-Sołacz verfügte über ein flaches Dach - von daher sollte innerhalb der Materialien aus Janowice die Abwesenheit von oval gebogenen Konstruktionselementen nicht überraschen (vgl. Dzięgielewski 2013, 23, 24). Auch die Abwesenheit von organischer Magerung (ein technologisches Merkmal, das bei allen Fragmenten aus Hrubiszów beobachtet wurde) und die hohe Brenntemperatur bei den Hüttenlehm-Gruppen 2 und 3 könnten auf die Funktion im Rahmen eines Ofens deuten. In diesen Zusammenhang sollte auch ein Hinweis von Olaf Strutzberg gebracht werden, der anhand der Auswertung von Brandruinen nachgebauter prähistorischer Hauser die Vermutung äußert, dass es sich bei den verziegelten Überresten meist um Ofenbestandteile handelt, da normalerweise die Brenntemperatur und Brenndauer eines ein Haus betreffenden Unglücksfeuers nicht ausreichen, um eine Konservierung des Rotlehms zu erreichen (Strutzberg 2006, 54). Darauf, dass nicht alle Hüttenlehmfragmente zu einer ofenartigen Struktur zugehörig sein sollten, weist jedoch die beidseitig konkave Form bei gleichzeitiger organischer Magerung des Fragmentes aus der Gruppe 1 hin (s. Kapitel Interpretation des Befundes 4/6 - Ein Wohnhaus). Zwar gibt es Ofeninstallationen, bei denen die Dachdeckung aus organisch gemagertem Rotlehm konstruiert wurde, es handelt sich aber dabei um kuppelförmige Strukturen, die in Flechtwerktechnik und nicht aus breiten Bohlen oder Spaltholzbohlen errichtet wurden (sehe z. B. Knoll/Fröhlich 2017, 184-186; Narożna-Szamałek/Szamałek 2003, 59).

Gegen die Interpretation des Befundes als zusammengebrochene Struktur in situ sprechen mehrere Beobachtungen. Vor allem gibt es bei dem Befund 4/6 keine Spuren von Auswirkungen der Hitze selbst in der Grube. Weder wurde die Grube mit Steinen verkleidet (wie es im Fall von Hrubieszów und Modlniczka beobachtet wurde), noch wurde der dem Befund benachbarte Löss verziegelt. Auch die gewaltige Dicke der plattenförmigen Fragmente und deren abgeflachte Form lässt sie nur sehr schwer als früheisenzeitliche Konstruktionsteile eines Grubenofens in Frage kommen. ${ }^{7}$

Falls die Ansprache als Ofen trotzdem im Betracht gezogen würde, sollte die Frage nach dem Zweck der Installation gestellt werden. Oben erwähnte Ofenkonstruktionen werden entweder als Keramik-, Kalk-, oder Backöfen interpretiert (z. B. Dzięgielewski 2013, 24). Für die ersten beiden Funktionsmöglichkeiten fehlen jegliche Hinweise. Dafür, dass es sich um eine Struktur handelt könnte, die mit der warmen Zubereitung von Speisen zusammenhängt, sprechen verkohlte Getreideüberreste, und das Kermikrepertoire - vor allem die Tonscheiben. Es besteht aber eine weitere Eventualität, der zufolge es sich dabei nicht um ein Ofeninstallation im "klassischen" Sinne handelt, sondern um die Überreste eines Hauses mit einer Herdplatte (s. Kapitel Interpretation des Befundes 4/6 - Szenario 3: Ein Haus mit Ofen und integrierter Darre).

\section{Szenario 2: Reste eines Wohnhauses mit einer Herdplatte}

Bei der zweiten Interpretation werden analog zum ersten Szenario die Hüttenlehmfagmente der Gruppe 1 als Reste einer Hauswand interpretiert. Die Platten (Hüttenlehm der Gruppe 3) könnten entweder Teile eines gestampftes Lehmboden sein, oder als Herdplatten funktioniert haben. Im ersten Fall - wenn wir die Beobachtungen von experimentellen Brandversuchen von M. Stevanović (1997, Tab. 4) auf unseren Befund direkt übertragen würden - hätte der Fußboden dort, wo die Feuerstelle eingerichtet wurde, sekundär gebrannt und wäre dadurch als Lehmplatte erhalten geblieben. Experimentelle Versuche beweisen, dass das Erreichen einer Temperatur von $900{ }^{\circ} \mathrm{C}$ auf einer offenen Feuerstelle, die

Mündliche Information von mgr. M. M. Przybyła.

7 Aus der Römischen Keiserzeit sind jedoch Kalköfen belegt, deren flache Dächer aus runden Hölzer konstruiert wurden und mit einer Lehmschicht von bis zum 20 cm bedeckt wurden (s. z. B. Święte 10; Wolanin 2009, 137, Abb. 88; für die Rekonstruktion eines Brennprozesses in einem solchen Ofen s. Wójcik 2008). 
$30 \mathrm{~cm}$ unterhalb des Bodennievaus konstruiert wurde, ohne weiteres machtbar ist (Wójcik 2008, 298). Vielleicht war der Boden des Hauses auch mit Holzspaltbohlen belegt (womöglich lassen sich auf der Unterseite mancher Fragmente Abdrücke der Hölzer erkennen). Die Platten aus Janowice erinnern an massive Lehmfußböden, die ab der Frühen Eisenzeit bis in die Römische Kaiserzeit in ganz Europa anzutreffen sind (Makiewicz 1976). Diese wurden vor allem in der älteren Literatur, dank nicht selten vorkommender geometrischer geritzter Verzierungen auf der Oberfläche und gleichzeitigem Auftreten von ungewöhnlichen Funden in deren Umgebung oft als "kultische" Objekte bezeichnet (Makiewicz 1976, 146). In den neuesten Studien wird eher eine Interpratetion im Rahmen der Nahrungszubereitung (v. a. Fladenbrote) vorgeschlagen (Griebl 2004, 189, 190). In Polen wurde ein ornamentierte Fußboden/ eine Feuerstelle in einem Haus auf dem früheisenzeitlichen Burgwall in Sobiejuchy, Pałuki, entdeckt (Harding/Ostoja-Zagórski/Strzałko 1991, 206, 207, Abb. 5). Im Westhallstattkreis wurden analoge Strukturen z. B. innerhalb der niederösterreichischen Siedlungen Göttlesbrunn (Griebl 2004, 188-190) oder Freuendorf (Schneidhofer 2010, 59-104, 247, 248, Abb. 61) dokumentiert. Ein weiteres früheisenzeitliches Verbreitungsgebiet befindet sich in der Ukraine und wird mit dem skythischen Kulturkreis in Zusammenhang gebracht (z. B. in Žabotin - Makiewicz 1976, 107-111, 134, Karte 1; Tab. 2).

Eine Variante so einer Installation wäre eine Herdeinrichtung, in der die Platten als ein Sockel über das Bodennieveau erhoben wären. Ähnliche Einrichtungen sind bekannt aus mehreren ethnografischen Vergleichen, z. B. in Mexiko (s. Griebl 2004, 188-190).

Gegen die beiden letztgenannten Interpretationen spricht vor allem die sekundäre Deponierung der Konstruktionsrotlehmstücke in der Grube und die Abwesenheit von Randstücken (vgl. aber Objekt 36 - Griebl 2004, 190). Auch wenn vorstellbar wäre, dass die Platten ursprünglich in der östlichen, flachen Seite des Befundes 4/6 lagen, wäre deren gezielte Redeponierung in der kreisförmigen Grube mit einem sehr großen Aufwand verbunden gewesen.

Die zweite Variante dieser Rekonstruktion wäre eine wannen-/beckenförmige Installation, eine sogenannte Darre. Solche Objekte sind aus äneolitischen Siedlungen, z. B. Askitario in Attika, bekannt und wurden auch auf zahlreichen frühmittelalterlichen Fundstellen dokumentiert, z. B. in Kraków Nowa Huta-Mogiła (Gluza/Kubica-Kabacińska 2005) oder auf dem Burgwall in Stradów (Szmoniewski/LityńskaZajac 2005). Es wird vermutet, dass die Darren als Installationen für das Rösten von Getreide verwendet wurden (Gluza/Kubica-Kabacińska 2005, dort weitere Literatur; Szmoniewski/Lityńska-Zajac 2005, dort weitere Literatur). Eine weitere Funktion im Rahmen der Nahrungsvorbereitung ist das Brotbacken, das in den Anlagen ebenso möglich wäre (Brzostowicz 2002, 85). Gegen den Vorschlag, dass es sich in Janowice um eine typische Darre handelte, spricht jedoch die Abwesenheit von Fragmenten des Rotlehms der Gruppe 3, bei denen ein Übergang des hypothetischen Bodens in die Randpartien erfasst werden kann.

\section{Szenario 3: Ein Haus mit Ofen und integrierter Darre}

Auf Siedlungen des 6. und 7. Jh. n. Chr. in Rumänien werden Darren rekonstruiert, die integrale Teile eines Ofens waren und als Bedachung im oberen Teil des Ofens montiert wurden (Dolinescu-Ferche 1995, Abb. 4B). Vielleicht sollte also der Konstruktionshüttenlehm aus der Grube 4/6 als ein Hybrid von einem Ofen mit flacher Herdplatte zum Rösten oder Backen vorgeschlagen werden.

\section{FAZIT}

Das Fundrepertoire, das aus der Grube 4/6 gewonnen wurde, spricht dafür, dass es sich bei den Überresten um Teile eines Gebäudes oder einer Gebäudeausstattung in der Art einer Herdinstallation handelt. Benachbarte, den Befund 4/6 umgebene Pfostengruben geben erste Hinweise auf eine mögliche Hauskonstruktion mit innenliegender Arbeitsgrube. Die technologische und typologische Ähnlichkeit der Konstruktionsrotlehmelemente sowie ihre Masse sprechen für intentionell gefertigte Strukturen im Rahmen des Hausbaus oder der Hauseinrichtung, die aufgrund unklarer Ursachen verbrannt und sekundär in die Grube gegeben wurden. Besonders interessant erscheinen die dicken Rotlehmplatten, die aufgrund ihrer thermischen Behandlung und der technologischen Merkmalen als Teile einer Ofen- oder Herdeinrichtung angesehen werden können. Es ist wahrscheinlich, dass es sich dabei um hitzeabhängige Nahrungsmittelzubereitung handeln könnte. Das in dem Haus Mahlzeiten vorbreitet wurden implizieren sowohl verkohlte Getreidekörner, Reib- und Pochsteine, als auch Keramikfragmente, vor allem 
die Tonscheiben. Ein nahezu vollständiges Webgewicht und ein weiteres Fragment eines Webgewichtes sprechen für einen Gewichtswebstuhl, der in dem Gebäude gestanden haben könnte. Interessanterweise findet die Stilistik mancher Funde (die Hornknubben, die Verzierung des Webgewichtes) gute Analogien in der östlicher Slowakei, was ein weiterer Hinweis für die Kontakte zwischen den beiden Regionen in der Früheizenzeit ist. Die Gesamtheit dieser Indizien lässt vermuten, dass wir hier einen früheisenzeitlichen Haushalt fassen können, der aufgrund eines Schadfeuers den Erhaltungsbedingungen des umgebenden mineralischen Bodens trotzen konnte und somit zumindest teilweise überliefert werden konnte.

\section{DANKSAGUNG}

Die Ausgrabungen auf der Fundstelle Janowice, Fdst. 6 (AZP 106-65/61), wurden im Rahmen des Projektes „Studien zur neolithischen und bronzezeitlichen Besiedlung und Wirtschaftsweise im Vorfeld der polnischen Westkarpaten", dank der finanziellem Unterstützung der Humbold-Stiftung möglich (Projektleitung: Prof. Dr. hab. P. Valde-Nowak, Prof. Dr. T. L. Kienlin). Die Hüttenlehm und Botanikanalysen wurden im Rahmen des Projektes: „Inheritance, social network or local adaptation? Bronze and Early Iron Age societies in Western Małopolska" (Grant-Nummer 2013/11/B/ HS3/04404, Projektleitung Prof. Dr. hab. Jan Chochorowski) durchgeführt. Für die hilfreichen Hinweise bei der Vorbereitung des Artikels möchten wir uns bei Klaus Cappenberg, Karol Dzięgielewski und Marcin M. Przybyła bedanken. Für die sprachliche Korrektur des Textes danken wir Klaus Cappenberg. 
Schnitt 4

Befund 6

Zwischenplanum 1-2

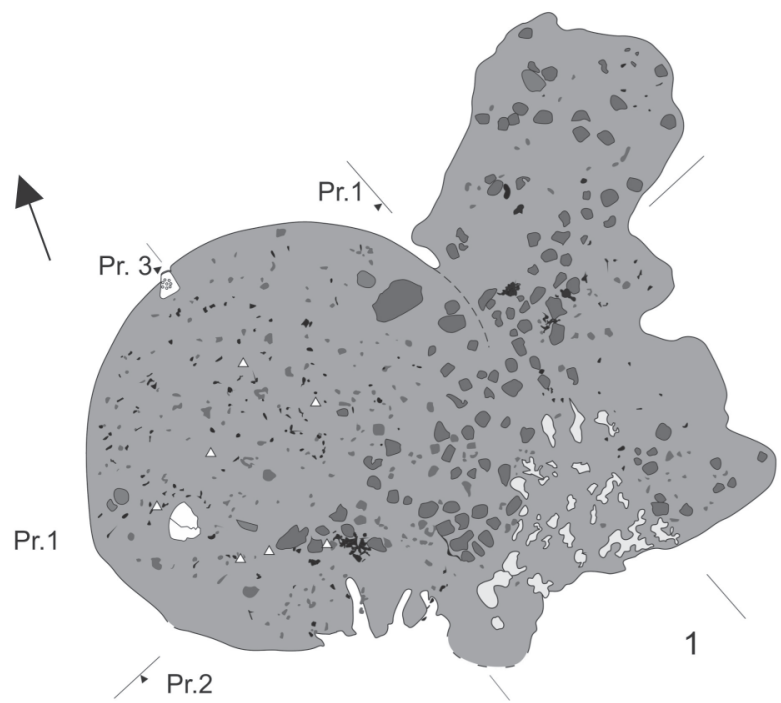

\section{Planum 2}

$\uparrow$
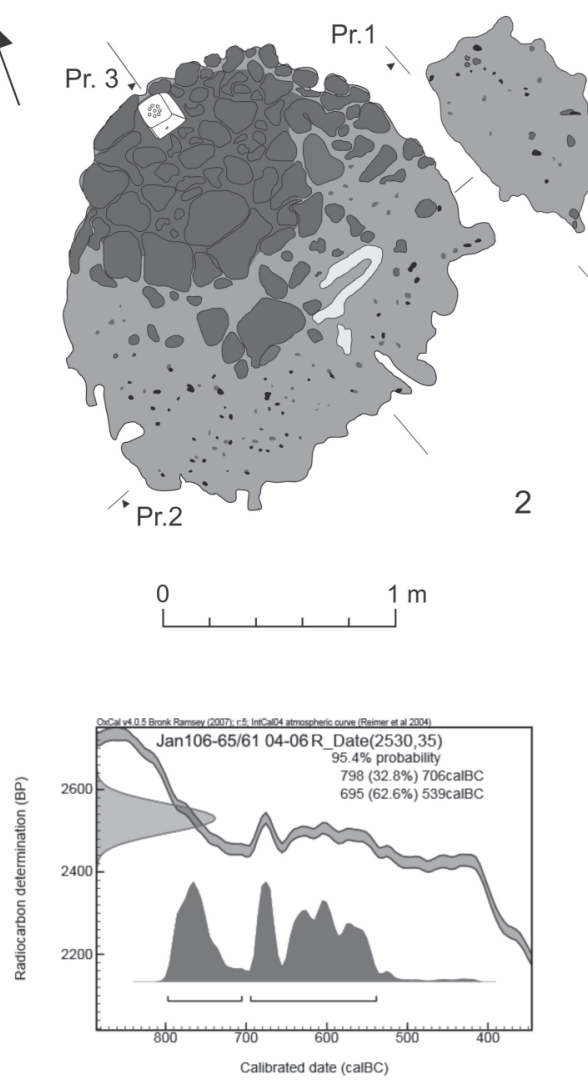

Pr. 1

N

Pr.2

Pr. 3
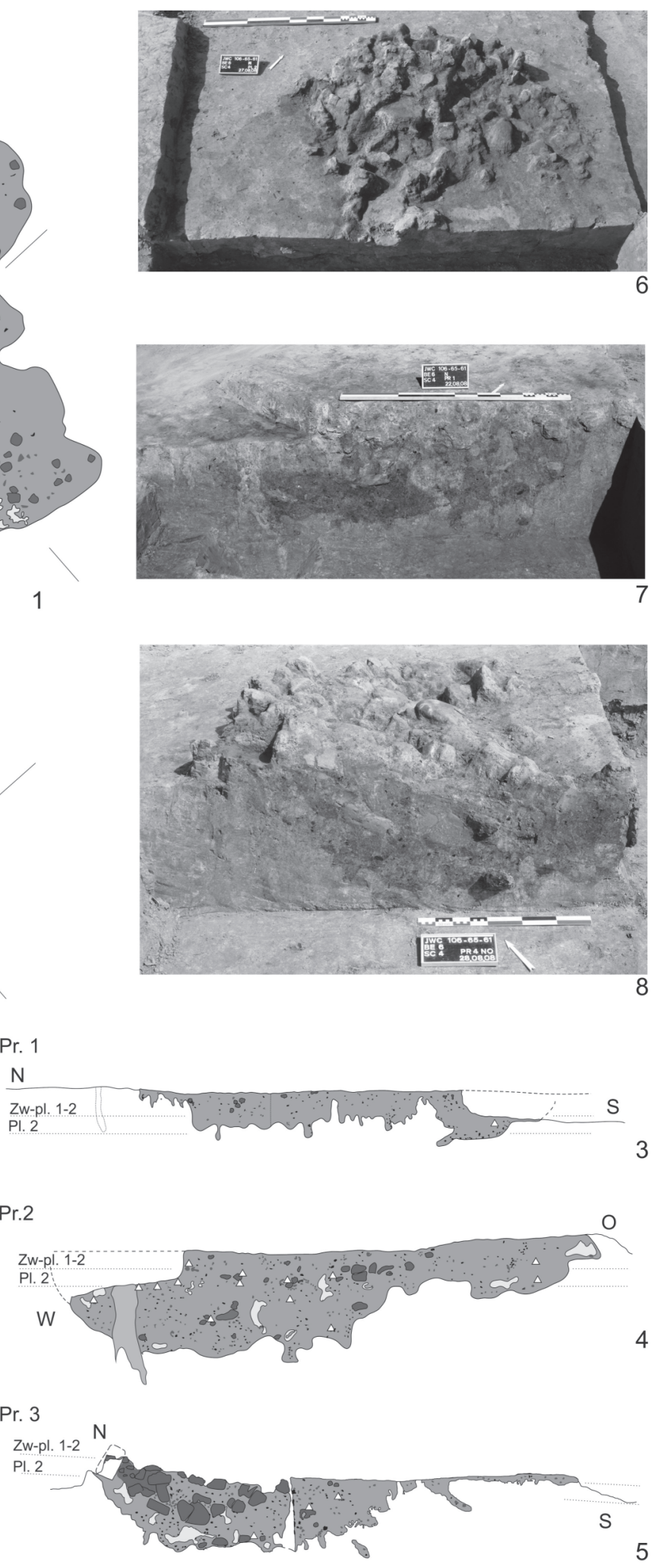

Taf. I. Janowice, Fdst. 6 (AZP 106-65/61), Pläne und Profile vom Befund 4/6. 
EIG'NER HERD IST GOLDES WERT
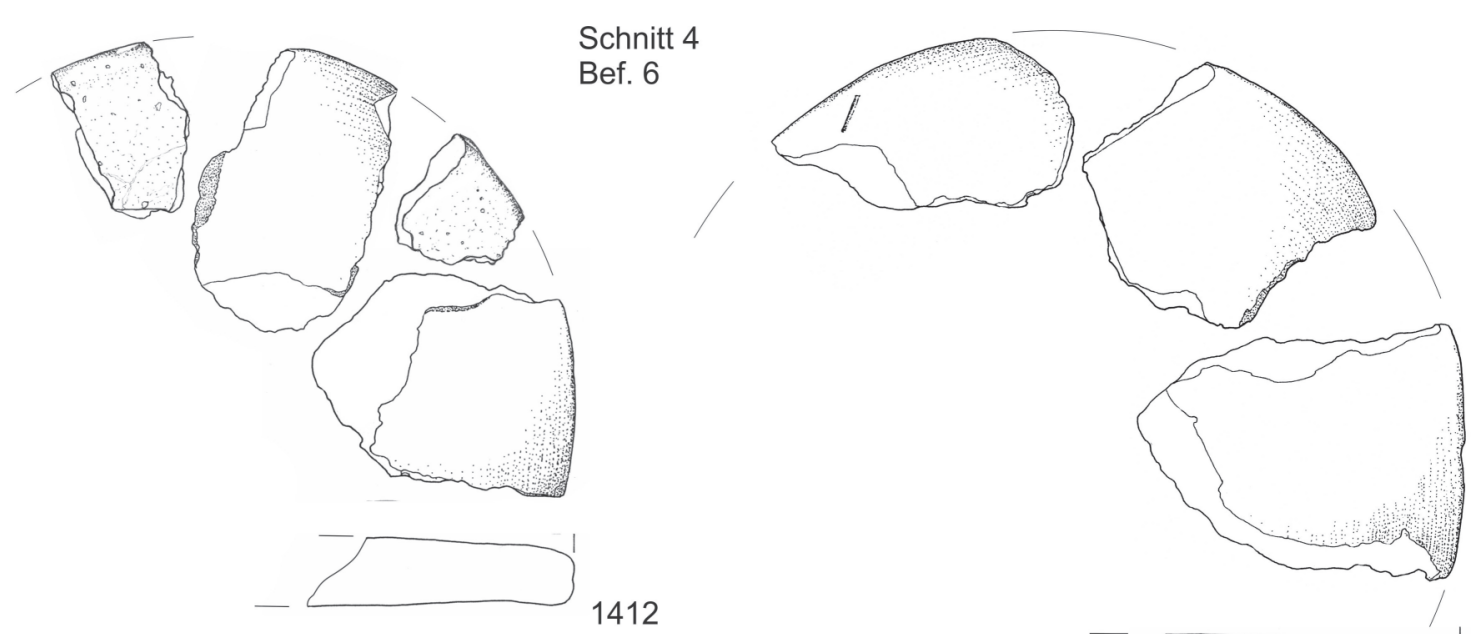

1412

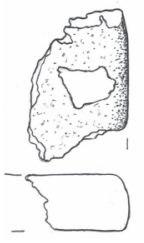

1455

1310

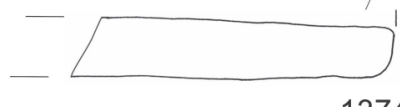

1374

Pons

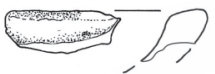
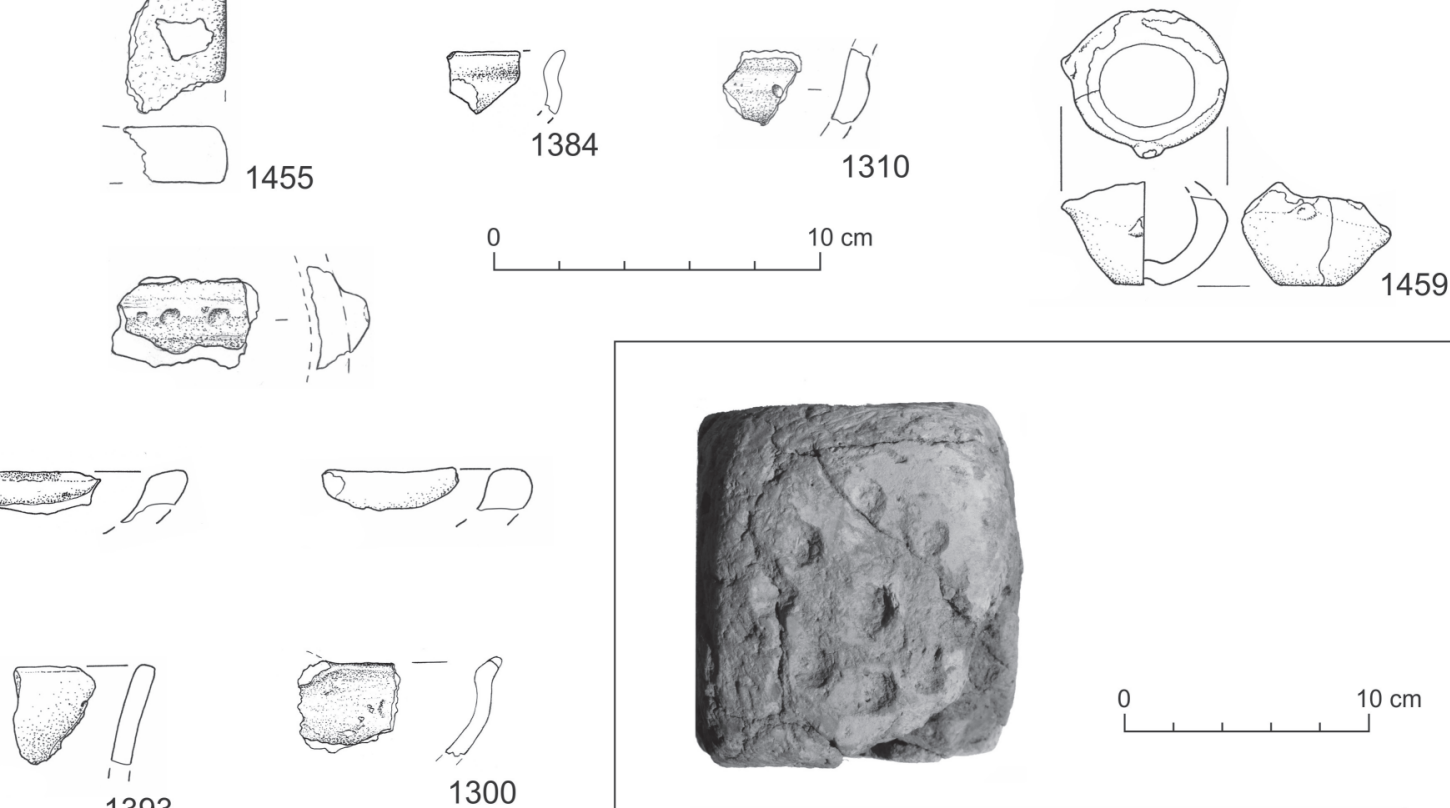

459

1393 1300
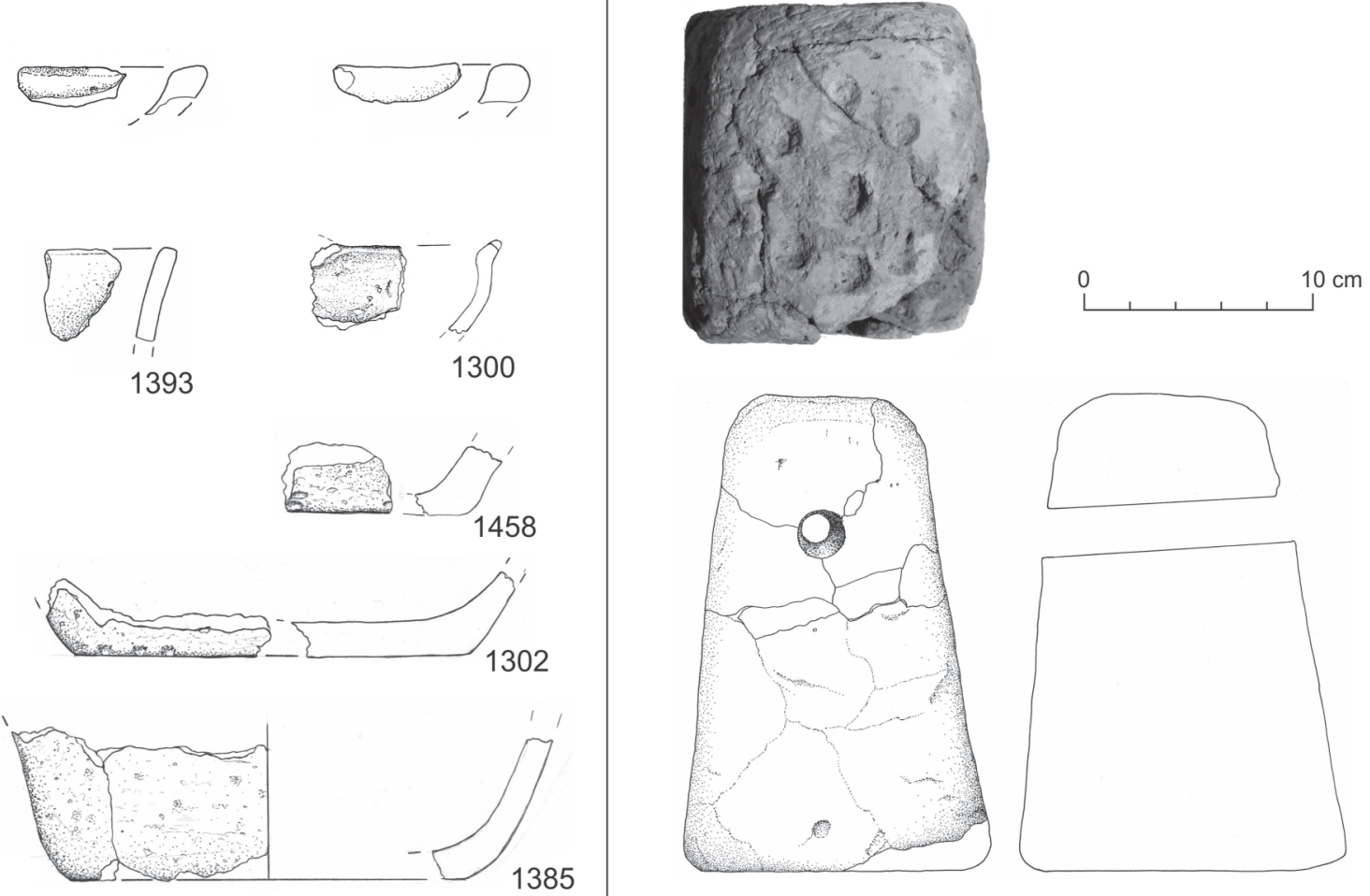

1385

Taf. II. Janowice, Fdst. 6 (AZP 106-65/61), Fundinventar aus der Verfüllung der Grube 4/6. 


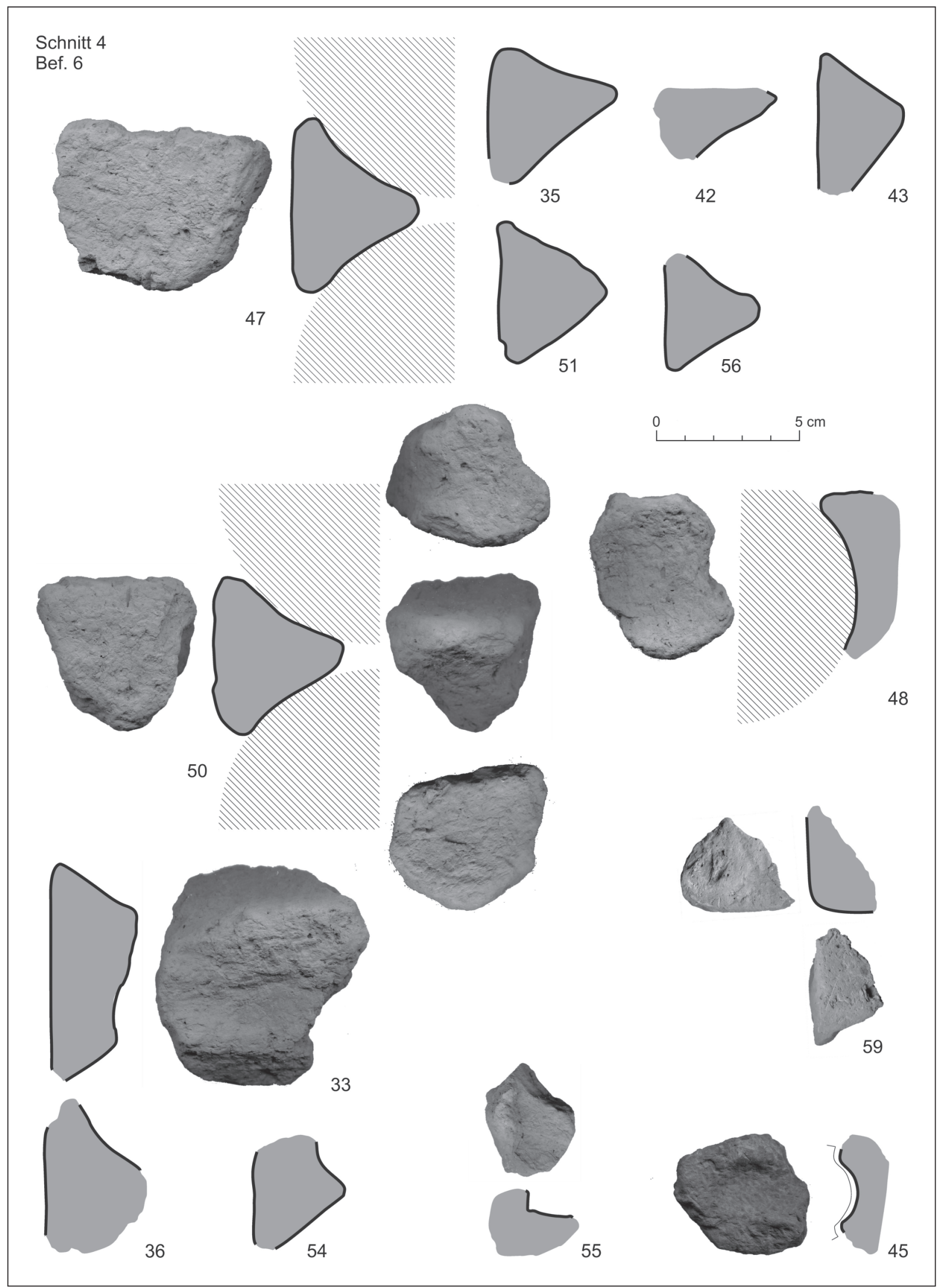

Taf. III. Janowice, Fdst. 6 (AZP 106-65/61), Konstruktionshüttenlehm der ersten Gruppe aus der Verfüllung der Grube 4/6. 


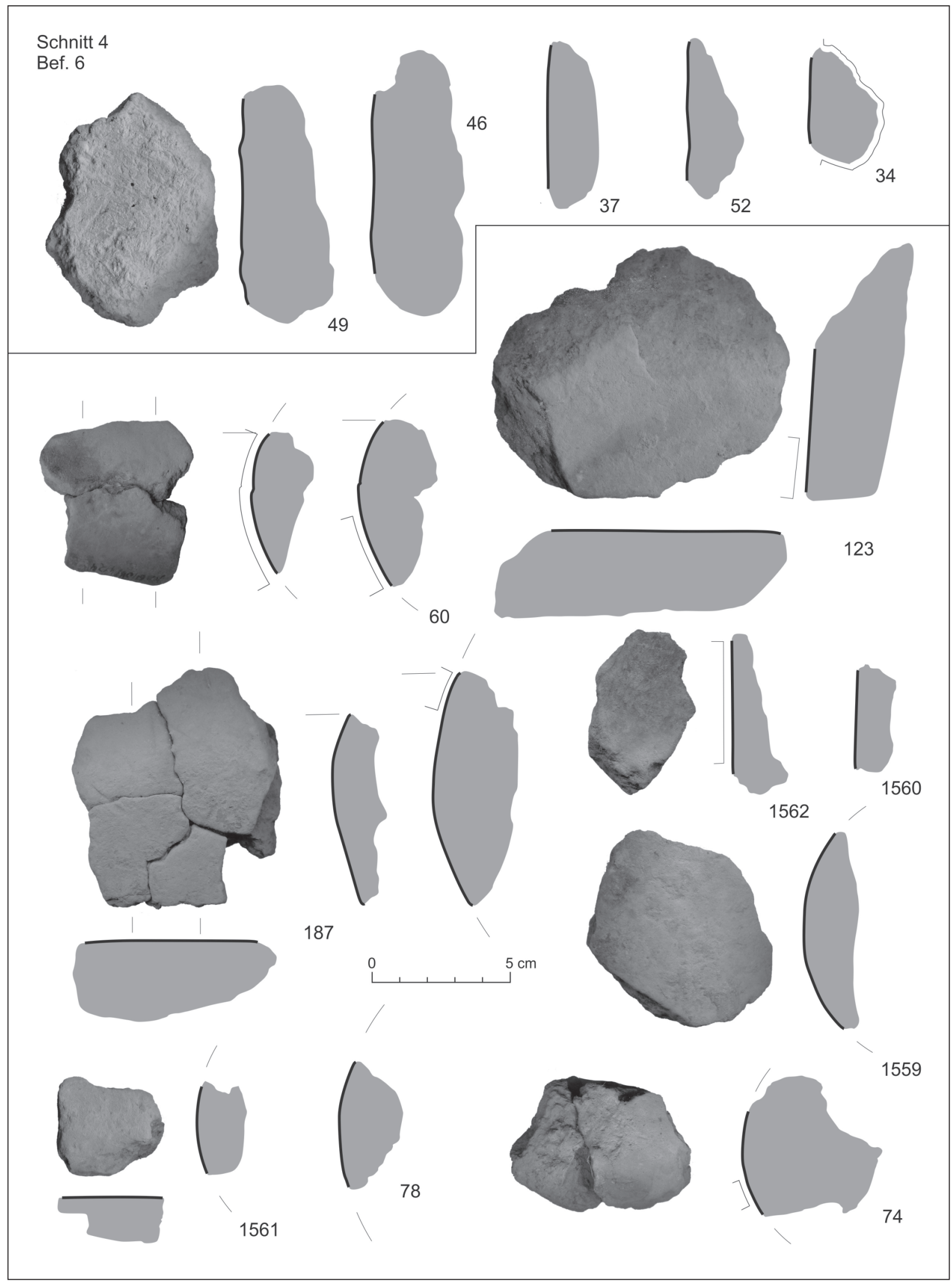

Taf. IV. Janowice, Fdst. 6 (AZP 106-65/61), Rotlehm der ersten Gruppe (oben) und der zweiter Gruppe (unten) aus der Verfüllung der Grube 4/6, 


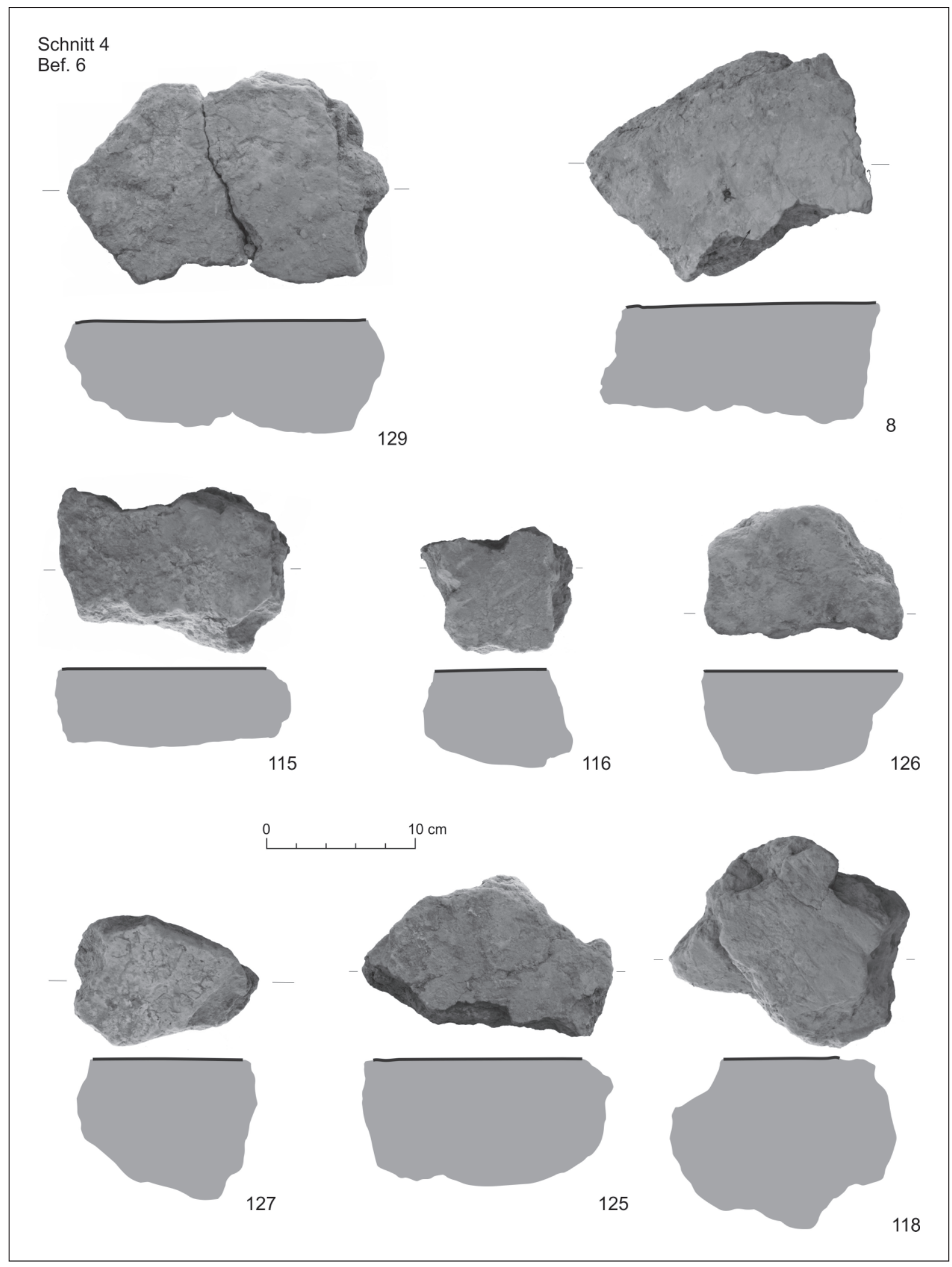

Taf. V. Janowice, Fdst. 6 (AZP 106-65/61), Konstruktionshüttenlehm der dritten Gruppe aus der Verfüllung der Grube $4 / 6$. 


\section{LITERATUR}

Baron/Karpow/Kużwik 2014

Baron/Stolarczyk 2012

Belanová/Čambal/Stegmann-Rajtár 2007

Budinský-Krička/Miroššayová 1992

Brzostowicz 2002

Cabalska/Madyda-Legutko/Tunia 1990

Choojka u. a. 2019

Dobiat 1990

Dolinescu-Ferche 1995

Ďurkovič 2015

Dzięgielewski 2010a

Dzięgielewski $2010 b$

Dzięgielewski 2013

Dziegielewski/Godlewski 2009

Gluza/Kubica-Kabacińska 2005

Gralak 2013

Griebl 2004

Haller/Gentizon-Haller 2012

Haller/Gentizon/Kuna 2007
J. Baron/J. Karpow/R. Kużwik: Osada z późnej epoki brązu i wczesnej epoki żelaza w Grabowcu, pow. jarosławski, woj. Podkarpackie. Raport 9, 2014, 53-115. J. Baron/T. Stolarczyk: Wznowienie badań wykopaliskowych na osadzie z epoki brązu i wczesnej epoki żelaza w Grzybianach w powiecie legnickim. Ślaskie Sprawozdania Archeologiczne 54, 2012, 101-127.

T. Belanová/R. Čambal/S. Stegmann-Rajtár: Die Weberin von Nové Košariská Die Webstuhlbefunde in der Siedlung von Nové Košariská im Vergleich mit ähnlichen Fundplätzen des östlichen Hallstattkulturkreises. Scripta Praehistorica In Honorem Biba Teržan. Situla 44. Ljubljana 2007, 419-434.

V. Budinský-Krička/E. Miroššayová: Terňa-Lysá stráž - sídlisko z neskorej doby bronzovej a halštatskej (Pokus o chronologické a kultúrne určenie). Slovenská archeológia 40/1, 1992, 47-76.

M. Brzostowicz: Bruszczewski zespót osadniczy we wczesnym średniowieczu. Prace Komiski Archeologicznej 22. Bibliotheca Fontes Archaeologici Posnanienses 10. Poznań 2002, 269-280.

M. Cabalska/R. Madyda-Legutko/K. Tunia: Wyniki badań stanowiska z epoki brązu, początkow epoki żelaza i z poźnego okresu rzymskiego w Nowym Sączu-Biegonicach. Acta Archaeologica Carpathica 29, 1990, 163-214.

O. Chvojka/P. Menšík/T. Šálková/M. Kuna: Tkalcovská závaží nebo podstavce pod rožně? Hliněná závaží ze sídelního areálu z mladší doby bronzové u Březnice (okr. Tábor) z pohledu archeologie a archeobotaniky. Archeologické rozhledy 71, 2019, 267-308.

C. Dobiat: Die Burgstallkogel bei Kleinklein I. Die Ausgrabungen der Jahre 1982-1985. Marburger Studien zur Vor- und Frühgeschichte 13. Marburg 1990.

M. Dolinescu-Ferche: Cuptoare din interiorul locuintelor din secolul al VI-lea e. n. de la Dulceanca. Studii si cercetari de istorie veche si arheologie 46, 1995, 161-192. É. Ďurkovič: Weaving-related finds from the Early Iron Age settlement at GyőrMénfőcsanak (Hungary). In: I. Szathmári/G. Ilon (Hrsg.): An der Grenze der Bronze- und Eisenzeit. Festschrift für T. Kemenczei. Budapest 2015, 81-107.

K. Dzięgielewski: Osada z młodszej i późnej epoki brązu na stanowisku $48 \mathrm{w}$ Wojniczu, pow. Tarnów. In: J. Chochorowski (Hrsg.): Via Archaeologica. Źródła z badań wykopaliskowych na trasie autostrady A4 w Małopolsce. Wojnicz 18 i 48, powiat Tarnów. Osady z epoki brazu, żelaza i średniowiecza. Kraków 2010, 55-116.

K. Dzięgielewski: Osada z wczesnej epoki żelaza na stanowisku 18 w Wojniczu, pow. Tarnów. In: J. Chochorowski (Hrsg.): Via Archaeologica. Źródła z badań wykopaliskowych na trasie autostrady A4 w Małopolsce. Wojnicz 18 i 48, powiat Tarnów. Osady z epoki brazu, żelaza i średniowiecza. Kraków 2010, 197-233.

K. Dzięgielewski: Hrubieszów, stanowisko 104. Osada z wczesnej epoki żelaza we wschodniej Lubelszczyźnie. Pękowice - Hrubieszów 2013.

K. Dzięgielewski/P. Godlewski: Wschodnie oddziaływania kulturowe na terytorium zachodniej Małopolski we wczesnej epoce żelaza - źródła i interpretacje. In: S. Czopek/K. Trybała (red.): Tarnobrzeska kultura łużycka - źródła i interpretacje. Rzeszów 2009, 191-225.

I. Gluza/E. Kubica-Kabacińska: Odciski roślinne na wczesnośredniowiecznych prażnicach ze stanowiska Kraków Nowa Huta Mogiła 62A. In: K. Wasylikowa/M. Lityńska-Zając/A. Bieniek (red.): Roślinne Ślady człowieka. Botanical Guidebook 28. Kraków 2005, 195-218.

T. Gralak: Budownictwo i styl w okresie halsztackim C na Dolnym Śląsku. Budownictwo i styl w okresie halsztackim C na Dolnym Śląsku. In: J. Kolenda/A. Mierzwiński/S.Moździoch/L.Żygadło (red.): Z badań nad kultura społeczeństw pradziejowych $i$ wczesnośredniowiecznych. Księga jubileuszowa dedykowana Profesorowi Bogusławowi Gedidze, w osiemdziesiata rocznice urodzin przez przyjaciót, kolegów i uczniów. Wrocław 2013, 329-348.

M. Griebl: Die Siedlung der Hallstattkultur von Göttlesbrunn, Niederösterreich. Rettungsgrabungen im Zuge des Ostautobahnbaus (A 4) im Jahre 1989. Mitteilungen der Prähistorischen Kommission 54. Wien 2004.

M. Haller/A.-L. Gentizon-Haller: Rekonstrukce stavební techniky pomocí mazanice z obj. 15.2. In: M. Kuna/A. Němcová (eds.): Výpověd’ sídlištního odpadu. Nálezy z pozdní doby bronzové v Roztokách a otázky depoziční analýzy archeologického kontextu. Praha 2012, 111-116.

M. Haller/A.-L.Gentizon/M. Kuna: Mazanice z pozdní doby bronzové z Roztok. Archeologické rozhledy 59, 2007, 765-778. 
Harding/Ostoja-Zagórski/Strzałko 1991

Jędrysik u. a., im Druck

Kienlin u. a. 2010

Knoll/Fröhlich 2017

Korczyńska/Mazur 2018

Kretschmer u. a. 2016

Lityńska-Zając/Moskal-del Hoyo/Cywa 2014

M. Lityńska-Zając/M. Moskal-del Hoyo/K. Cywa: Plant remains found in archäological sites in the Carpathian Foothills - Preliminary report. In: T. L. Kienlin/P. Valde-Nowak/M. Korczyńska/K. Cappenberg/J. Ociepka (eds.): Settlement, Communications and Exchange around the Western Carpathians. International Workshop held at the Institute of Archaeology, Jagiellonian University, Kraków, October 27-28, 2012. Oxford 2014, 207-221.

Lityńska-Zając u. a. 2017

Lityńska-Zają/Wasylikowa 2005

Makiewicz 1976

Madyda-Legutko 1995

Michalski 1983

Miraś/Oleszczak 2014

Mirek u. a. 2002

Mirroššayová 1994

Molnár/Farkaš 2010

A. F. Harding/J. Ostoja-Zagórski/J. Strzałko: Archeologiczno-przyrodnicze badania mikroregionalne w Sobiejuchach koło Żnina. In: J. Jaskanis (red.): Prahistoryczny gród w Biskupinie. Problematyka osiedli obronnych na początku epoki żelaza. Warszawa 1991, 197-215.

J. Jędrysik/J. Markiewicz/E. Rydzewska/J. Rzońca: Rezultaty analiz chronologiczno-przestrzennych materiałów $z$ dawnych badań prehistorycznej osady wyżynnej w Zabrzeży, pow. nowosadecki. Im Druck.

T. L. Kienlin/K. Cappenberg/M. M. Korczyńska/M. S. Przybyła/P. W. Valde-Nowak: Peripherie oder Kommunikationsraum? Siedlungsarchäologische Untersuchungen im Vorfeld der polnischen Westkarpaten (Wiśnicz-Hügelland und mittleres Dunajectal, Kleinpolen). In: B. Horejs/T. L. Kienlin (Hrsg.): Siedlung und Handwerk. Studien zu sozialen Kontexten in der Bronzezeit. Universitätsforschungen zur prähistorischen Archäologie 194. Bonn 2010, 191-267.

F. Knoll/M. Fröhlich: Wände, Böden und andere Strukturen - verziegelte Lehmfragmente als Qülle zur Rekonstruktion von Gebäuden. In: H. Meller/M. Becker (Hrsg.): Në̈ Gleise auf alten Wegen II Jüdendorf bis Gröbers. Archäologie Sachsen-Anhalt. Sonderband 26. Halle 2017, 176-190.

M. Korczyńska/M. Mazur: Unterschiedlich und doch gleich? Eine komparative Studie zu spätbronze-/früheisenzeitlichen Webgewichten aus Kleinpolen. In: L. Benediková/L. Horňák (eds.): Sídla, artefakty a čas... Zborník štúdií o dobe bronzovej a dobe halštatskej $k$ 75. narodeninám Ladislava Veliačika. Nitra - Vrútky 2018, 171-198.

S. Krestchmer/P. Viol/H. Stäuble/Ch. Herbig/B. Muigg/W. Tegel/Ch. Tinapp: Der Fundplatz Droßdorf im Tagebaufeld Peres (Lkr. Leipzig). Ein früh-, mittelund spätneolithisches Siedlungsareal mit zahlreichen Brunnen. In: R. Smolnik (Hrsg.): Ausgrabungen in Sachsen 5. Arbeits- und Forschungsberichte zur sächsischen Bodendenkmalpflege. Beiheft 31. Dresden 2016, 30-57.

M. Lityńska-Zając/M. Moskal-del Hoyo/A. Müller-Bieniek/A. Wacnik: Stan i problematyka badań archeobotanicznych w polskiej części Karpat (State of the art and problems in archaeobotanical research of the Polish Carpathian lands). In: J Gancarski (red.): Stan i problematyka badań archeobotanicznych w polskiej części Karpat. Stan i potrzeby badań archeologicznych w Karpatach. Krosno 2017, 719-750.

M. Lityńska-Zając/K. Wasylikowa: Przewodnik do badań archeobotanicznych (Guidebook to archäobotanical studies, in Polish). Poznań 2005.

T. Makiewicz: Ołtarze i ,paleniska” ornamentowane z epoki żelaza w Europie. Przeglad Archeologiczny 24, 1976, 103-183.

R. Madyda-Legutko: Sytuacja kulturowa we wczesnej epoce żelaza na terenie polskiej części Karpat Zachodnich. In:. J. Szydłowski (red.): Dziedzictwo kulturowe epoki brazu i wczesnej epoki żelaza na Górnym Ślasku i w Małopolsce. Śląskie Prace Prehistoryczne 4. Katowice 1995, 241-265.

J. Michalski: Zagadnienia systematyzacji i interpretacji obiektów nieruchomych (Ze studiów nad osadami otwartymi kultury łużyckiej). Materiały starożytne $i$ wczesnośredniowieczne 5, 1983, 135-196.

I. Miraś/Ł. Oleszczak: Transcarpathian inflünces on the Bronze Age and the Early Iron Age settlement at Wierzchosławice site 15. In: Kienlin/P. ValdeNowak/M. Korczyńska/K. Cappenberg/J. Ociepka (eds.): Settlement, Communication and Exchange around the Western Carpathians. International Workshop held at the Institute of Archaeology, Jagiellonian University, Kraków, October 27-28, 2012. Oxford 2014, 297-316.

Z. Mirek/H. Piękoś-Mirek H/A. Zając/M. Zając: Flowering plants and pteridophytes of Poland. A checklist. Biodiversity of Poland 1. Kraków 2002.

E. Miroššayová: Sídlisko z neskorej doby halštatskej v Čečejovciach. Slovenská archeológia 42, 1994, 37-68.

A. Molnár/Cs. Farkas: Hallstattzeitlicher Tonaltar aus Vát. Angaben zu den „Kultgegenständen“ der Osthallstattkutur. Acta Archaeologica Academiae Scientiarum Hungaricae 61, 2010, 107-143. 
Moskal-del Hoyo u. a. 2015

Moskal-del Hoyo u. a. 2017

Müller 2012

Narożna-Szamałek/Szamałek 2003

Podbielkowski 1985

Przybyła, M. S. 2009

Przybyła, M. S./Przybyła, M. M. 2010

Půlpánová-Reszczyńska 2015

Rajewski 1950

Schneidhofer 2010

Skoneczna 2014

Stäuble/Campen 1998

Stevanović 1997

Stegmann-Rajtár 1998

Strutzberg 2006

Szmoniewski/Lityńska-Zajac 2005

Teržan 1990

Tomanek 1987

Vařeka 2012

Warywoda 1957

Wasilewski 2014
M. Moskal-del Hoyo/M. Lityńska-Zając/M. Korczyńska/K. Cywa/T. L. Kienlin/K. Cappenberg: Plants and environment: results of archäobotanical research of the Bronze Age settlements in the Carpathian Foothills in Poland. Journal of Archaeological Science 53, 2015, 426-444.

M. Moskal-del Hoyo/A. Rauba-Bukowska/M. Lityńska-Zając/A. MüllerBieniek/A. Czekaj-Zastawny: Plant materials used as temper in the oldest Neolithic pottery from south-eastern Poland. Vegetation History and Archaeobotany 26, 2017, 329-344.

S. Müller: Smolenice-Molpír, Sered' und Ratkovce. Studien zu Siedlungen der frühen Eisenzeit in der Südwestslowakei. Universitätsforschungen zur prähistorischen Archäologie 220. Bonn 2012.

U. Narożna-Szamałek/K. Szamałek: Zasiedlenie terenów powiatu wrzesińskiego w młodszej epoce brązu i wczesnej epoce żelaza w świetle wyników badań przeprowadzonych w ramach Archeologicznego Zdjęcia Polski. In: W. Brzostowicz (red.): Archeologia powiatu wrzesińskiego. Wrzesnia 2003, 41-62.

Z. Podbielkowski: Słownik roślin użytkowych. Warszawa 1985.

M. S. Przybyła: Intercultural contacts in the Western Carpathian area at the turn of the $2^{\text {nd }}$ and $1^{\text {st }}$ millennia BC. Warszawa 2009.

M. S. Przybyła/M. M. Przybyła: Osada z okresu halsztackiego w Modlniczce, pow. Kraków, w świetle kontaktów z terenami zakarpackimi. In: J. Gancarski (red.): Transkarpackie kontakty kulturowe w epoce kamienia, brazu i wczesnej epoce żelaza. Krosno 2015, 529-574.

A. Půlpánová-Reszczyńska: Interpretacja polepy odkrytej na osadzie wielokulturowej na przykładzie stanowiska nr 1 w Zamiechowie, pow. Jarosławski. Materiały i Sprawozdania Rzeszowskiego Ośrodka Archeologicznego 36, 2015, 181-197.

Z. Rajewski: Budowle grodów kultury łużyckiej na półwyspie jeziora biskupińskiego w powiecieżnińśkim. In: J. Kostrzewski (red.): III. Sprawozdanie z prac wykopaliskowych w grodzie kultury łużyckiej w Biskupinie w powiecie żnińskim za lata 1938-1939 i 1946-1948. Poznań 1950, 239-285.

P. Schneidehofer: Die hallstattzeitliche Siedlung von Freundorf. Diplomarbeit (Universität Wien). Wien 2010. Unpubliziert. http://othes.univie.ac.at/8518/ [01. 03. 2018].

M. Skoneczna: Wyniki badań wykopaliskowych wschodniej krawędzi stanowiska w Maszkowicach (pow. Nowy Sacz) przeprowadzonych w sezonach 2010 i 2011 - rekonstrukcja procesu formowania sie stanowiska archeologicznego. Magisterarbeit (Uniwersytet Jagielloński). Kraków 2014. Unpubliziert.

H. Stäuble/I. Campen: 7000 Jahre Brunnenbau im Südraum von Leipzig. In: H. Koschik (Hrsg.): Brunnen der Jungsteinzeit. Köln - Bonn 1998, 51-71.

M. Stevanović: The Age of Clay: The Social Dynamics of House Destruction. Journal of Anthropological Archaeology 16, 1997, 334-339.

S. Stegmann-Rajtár: Spinnen und Weben in Smolnice-Molpír. Ein Beitrag zum Wirtschaftlichen und religiös-kultischen Leben der Bewohner des hallstattzeitlichen „Fürstensitzes“. Slovenská archeológia 46, 1998, 263-287.

O. Strutzberg: Ergebnisse der Untersuchungen abgebrannter Hausbauten der Experimentellen Archäologie. In: F. Both (Hrsg.): Experimentelle Archäologie in Europa. Bilanz 2005, 4, 51-58.

Sz. Szmoniewski/M. Lityńska-Zając: Prażnice z wczesnośredniowiecznego grodziska w Stradowie, gm. Czarnocin In: K. Wasylikowa/M. Lityńska-Zając/A. Bieniek (red.): Roślinne Ślady człowieka. Botanical Guidebook 28. Kraków 2005, 219-230.

B. Teržan: Starejša železna doba na Slovenskem Štajerskem. Katalogi in monografije 25. Ljubljana 1990.

J. Tomanek. Botanika leśna. Warszawa 1987.

P. Vařeka: Mazanice. In: M. Kuna/N. Němcová et al.: Výpověd' sídlištního odpadu. Nálezy z pozdní doby bronzové v Roztokách a otázky depoziční analýzy archeologického kontextu. Praha 2012, 105-111.

A. Warywoda: Encyklopedia techniczna I. Drzewa użytkowe w architekturze przestrzennej i przemyśle A-Z. Ważniejsze gatunki iglaste i liściaste produkujace drewno $i$ inne surowce znane na międzynarodowych rynkach handlowych. Kraków 1957.

M. Wasilewski: Stones Collecting and Preliminary Discrimination on the Archaeological Site - Janowice (AZP 106-64 no. 61) Case Study. In T. L. Kienlin/P. Valde-Nowak/M. Korczyńska/K. Cappenberg/J. Ociepka (eds.): Settlement, Communications and Exchange around the Western Carpathians. International Workshop 
Wójcik 2008

Wolanin 2009

Zimmermann 1998 held at the Institute of Archaeology, Jagiellonian University, Kraków, October 27-28, 2012. Oxford 2014, 223-230.

A. Wójcik: Próba odtworzenia pradziejowej techniki wypalania wapna na podstawie odkryć na osadzie ludności kultury przeworskiej w miejscowości Kamień, stan. 2, pow. bełchatowski, woj. łódzkie. In: J. Skowron/M. Olędzki (red.): Kultura przeworska. Odkrycia - interpretacje- hipotezy II. Łódź 2008, 493-505.

P. Wolanin: Polepa. In: A. Jaszewska/A. Leciejewska/H. Machajewski/E. Pawlak/P. olanin (Hrsg.): Opracowanie wyników ratowniczych badań archeologicznych na stanowisku nr 10 w Świętem, gm. Stargard Szczecinski, woj. Zachodniopomorskie. Poznań 2009, 141-145.

W. H. Zimmermann: Pfosten, Ständer und Schwelle und der Übergang vom Pfostenzum Ständerbau - Eine Studie zu Innovation und Beharrung im Hausbau. Zu Konstruktion und Haltbarkeit prähistorischer bis neuzeitlicher Holzbauten von den Nordund Ostseeländern bis zu den Alpen. Probleme der Küstenforschung im südlichen Nordseegebiet 25. Oldenburg 1998, 9-241.

\section{Pec nad zlato}

\section{Mimoriadna nálezová situácia na sídlisku Janowice, nálezisko 6 (AZP 106-65/61), v pol’ských Západných Karpatoch}

Marta Korczyńska - Maria Lityńska-Zając - Magdalena Moskal-del Hoyo

Súhrn

V roku 2008 bola na sídlisku v Janowiciach 6 (pohorie Rożnów v predhorí Západných Karpát) odkrytá sídlisková jama 4/6 datovaná do staršej doby železnej, v ktorej sa našli významné nálezy, a tiež vel'ký počet kusov mazanice s dokladmi konštrukčných prvkov. Váha odkrytých fragmentov dosiahla približne $40 \mathrm{~kg}$, a tým výraznou mierou prekročila celkovú hmotnost’ mazanice zo všetkých ostatných objektov preskúmaných na sídlisku. Na rekonštrukciu funkcie sídliskovej jamy s mazanicou sa vykonali podrobné typologické, technologické a archeobotanické analýzy, a zároveň sa uskutočnil aj karpologický a antrakologický výskum ich depozičného kontextu. Na základe toho bola mazanica, na ktorej sme zistili odtlačky konštrukčných prvkov, rozdelená do troch skupín: 1. klinovité a obojstranne zúžené fragmenty, ktoré sa pôvodne s vel'kou pravdepodobnostou nachádzali medzi dvomi širokými gul'atinami alebo štiepanými brvnami; 2. na vonkajších stranách zaoblené alebo (menej často) zúžené fragmenty s vel’kou prímesou sludy, ktorá sa vyznačovala výraznou kompaktnou štruktúrou a hladkým, čiastočne redukčne vypáleným povrchom; 3. extrémne masívne, kompaktné, jednostranne zúžené a hladené doskovité kusy - možno aj sekundárne prepálené zvyšky hlineného výmazu podlahy. Archeobotanické výskumy doložili, že pri všetkých troch uvedených skupinách mazanice sa využívala organická prímes; táto pozostávala z fragmentov konárikov, ako aj z menších a väčších fragmentov z obilných býl: pšenice jednozrnovej a/alebo pšenice dvojzrnovej, a tiež z plano rastúcich tráv. Tieto postupy pravdepodobne zvyšovali elasticitu substrátu, zabraňovali výskytu trhlín a celkovo tak vytvorili mazanicu, ktorá bola odolnejšia voči vonkajším vplyvom ovzdušia. Dubové drevo, ktoré sa zachovalo v jednej z doskovitých kusov tretej skupiny mazanice, dovoluje predpokladat, že sa tento typ dreviny využíval aj ako konštrukčné drevo. Z okolia mazanice tejto skupiny sa získali tiež viaceré zuhol’natené zvyšky duba (Quercus sp.), ktorý spolu s dvomi d’alšími tvrdými drevinami - bukom lesným (Fagus sylvatica) a hrabom obyčajným (Carpinus betulus), patrili k trom najčastejšie zastúpeným taxónom. Na základe toho sa domnievame, že pri mazanici prvej skupiny ide o konštrukčné prvky takej stavby, ktorá bola vybudovaná rámovou technikou, teda o zvyšky možno kombinovanej stavebnej techniky s využitím obvodových a nosných kolov, alebo - čo je menej pravdepodobné, o časti stavby, ktorá bola postavená zrubovou technikou. Na základe termického spracovania a zistených technologických vlastností sa dosky mazanice, ktoré dosiahli hrúbku až do $11 \mathrm{~cm}$, a ktoré boli zaradené do tretej skupiny, môžu s vel'kou pravdepodobnostou považovat' za súčasti pece alebo ohniska. Dá sa predpokladat', že v tomto prípade išlo o zariadenia na tepelnú prípravu pokrmov a tepelnú úpravu rôznych potravín, aj ked’ presné doklady o týchto procesoch, ako aj ich jednoznačná rekonštrukcia dodnes absentujú, a zároveň chýbajú aj rekonštrukcie takýchto tepelných zariadení. $Z$ tohto dôvodu boli navrhnuté tri možnosti interpretácie, ktoré boli zároveň predmetom detailnej diskusie. Podla toho by mohlo íst’ o zahíbenú pec alebo o ohnisko s výmazom, prípadne o pec s integrovaným roštom. Nezávisle od toho, ktorá z uvedených troch navrhnutých možností najpravdepodobnejšia, a bola by dokladom procesu, ako sa v príslušnom obydlí pripravovalo 
jedlo, potvrdzuje názor o príprave jedla práve výskyt zuholnnatených zŕn obilnín a strukovín (o. i. jačmeňa siateho Hordeum vulgare, neurčené druhy obilnín exempláre Cerealia indet., ako aj semien hrachu siateho Pisum sativum), a tiež na základe nálezov zrnotierok a drvidiel, ako aj fragmentov keramiky, predovšetkým hlinených kotúčikov. Jedno takmer kompletne zachované tkáčske závažie a fragment d’alšieho tkáčskeho závažia dovolujú zároveň usudzovat o prítomnosti tkáčskych krosien, ktoré mohli byt̉ umiestnené priamo v obydlí. Kolové jamy okolo objektu 4/6 ukazujú na konštrukciu domu s vnútornou pracovnou jamou. Súbor indícii poukazuje na skutočnosṫ, že sa nám podarilo odkryt’ zvyšok inventára domu zo staršej doby železnej, ktorý sa zachoval aj vd’aka ničivému požiaru, ktorý vysušil okolitú pôdu bohatú na minerály, čím nám zakonzervoval aspoň čast’ informácií.

Obr. 1. Pohl’ad na sídlisko v Janowiciach, nálezisko 6 (AZP 106-65/61), a na okolité lokality severozápadne od neho (foto K. Cappenberg).

Obr. 2. Janowice, nálezisko 6 (AZP 106-65/61), plán rezu 4.

Obr. 3. Porovnanie hlineného tkáčskeho závažia s nálezmi z rezov 3-9 v Janowiciach, nálezisko 6 (AZP 106-65/61).

Obr. 4. Typy odtlačkov konštrukčných prvkov na mazanici z nál. komplexu 4/6.

Obr. 5. Porovnanie technológie na konštrukčných prvkoch mazanice a výber troch z jej najčastejšie sa vyskytujúcich foriem v nál. komplexe 4/6.

Obr. 6. Rozptyl hrúbky všetkých doskovitých fragmentov mazanice na sídlisku v Janowiciach, nálezisku 6 (AZP 10665/61).

Obr. 7. Výsledky antrakologickej analýzy a priestorového rozmiestnenia pôdnych vzoriek v nál. komplexe 4/6.

Obr. 8. Fragment uhlíka Fagus sylvatica z nál. komplexu 4/6 (vzorka č. 32) a jeho anatomické prierezy: a - rezná plocha; b - tangenciálna plocha; c - radiálna plocha.

Obr. 9. Návrh rekonštrukcie obytnej stavby zo staršej doby železnej v priestore sídliskového objektu 4/6.

Tabela 1. Janowice, nálezisko 6 (AZP 106-65/61), mazanica s konštrukčnými prvkami z nál. komplexu 4/6.

Tabela 2. Janowice, nálezisko 6 (AZP 106-65/61), makroskopické zvyšky rastlín z pôdnych vzoriek. Stav zachovania: vzuholnatené, uv - bez stôp zuholnatenia; typ zvyškov: f - plod, s - semeno, k - obilné zrno, wk - rizóm, sp - pleva.

Tabela 3. Janowice, nálezisko 6 (AZP 106-65/61), uhlíky z pôdnych vzoriek. Stav zachovania: v - zuhol’natené; typ zvyškov: h - uhlíky.

Tabela 4. Janowice, nálezisko 6 (AZP 106-65/61), odtlačky rastlín na mazanici. Stav zachovania: v - zuhol’natené, a odtlačok, g - spečené; typ zvyškov: k - obilné zrno, ag - vidličky, sp - úlomky kláskov, h - drevo, bl - list.

Tabela 5. Janowice, nálezisko 6 (AZP 106-65/61), makroskopické zvyšky rastlín z nál. komplexu 4/6, datované do horizontu neskorej doby bronzovej/staršej doby železnej. Vysvetlivky a skratky - pozri tabely 1; 2 .

Tab. I. Janowice, nálezisko 6 (AZP 106-65/61), plány a profily nál. komplexu 4/6.

Tab. II. Janowice, nálezisko 6 (AZP 106-65/61), nálezový inventár z výplne jamy 4/6.

Tab. III. Janowice, nálezisko 6 (AZP 106-65/61), mazanica s konštrukčnými prvkami prvej skupiny z výplne jamy 4/6.

Tab. IV. Janowice, nálezisko 6 (AZP 106-65/61), mazanica prvej skupiny (hore) a mazanica druhej skupiny (dole) z výplne jamy $4 / 6$.

Tab. V. Janowice, nálezisko 6 (AZP 106-65/61), mazanica s konštrukčnými prvkami tretej skupiny z výplne jamy 4/6.

Translated by the authors Preložila Susanne Stegmann-Rajtár

Mgr. Marta Korczyńska

Zakład Paleobotaniki

Instytut Botaniki im. W. Szafera PAN

Lubicz 46

PL - 31-512 Kraków

martakorczynska@poczta.onet.pl

Magdalena Moskal-del Hoyo, PhD.

Zakład Paleobotaniki

Instytut Botaniki im. W. Szafera PAN

Lubicz 46

PL - 31-512 Kraków

m.moskal@botany.pl
PhD habil. Maria Lityńska-Zając

Instytut Archeologii i Etnologii PAN

Sławkowska 17

PL - 31-016 Kraków

marialitynska@gazeta.pl 
